\title{
Seismic performance of buried electrical cables: evidence-based repair rates and fragility functions
}

\author{
I. Kongar ${ }^{1}$ - S. Giovinazzi ${ }^{2}$ T. Rossetto ${ }^{1}$
}

Received: 13 April 2016/Accepted: 21 December 2016/Published online: 31 December 2016

(C) The Author(s) 2016. This article is published with open access at Springerlink.com

\begin{abstract}
The fragility of buried electrical cables is often neglected in earthquakes but significant damage to cables was observed during the 2010-2011 Canterbury earthquake sequence in New Zealand. This study estimates Poisson repair rates, similar to those in existence for pipelines, using damage data retrieved from part of the electric power distribution network in the city of Christchurch. The functions have been developed separately for four seismic hazard zones: no liquefaction, all liquefaction effects, liquefactioninduced settlement only, and liquefaction-induced lateral spread. In each zone six different intensity measures (IMs) are tested, including peak ground velocity as a measure of ground shaking and five metrics of permanent ground deformation: vertical differential, horizontal, maximum, vector mean and geometric mean. The analysis confirms that the vulnerability of buried cables is influenced more by liquefaction than by ground shaking, and that lateral spread causes more damage than settlement alone. In areas where lateral spreading is observed, the geometric mean permanent ground deformation is identified as the best performing IM across all zones when considering both variance explained and uncertainty. In areas where only settlement is observed, there is only a moderate correlation between repair rate and vertical differential permanent ground deformation but the estimated model error is relatively small and so the model may be acceptable. In general, repair rates in the zone where no liquefaction occurred are very low and it is possible that repairs present in this area result from misclassification of hazard observations, either in the raw data or due
\end{abstract}

I. Kongar

indranil.kongar.10@ucl.ac.uk

S. Giovinazzi

sonia.giovinazzi@canterbury.ac.nz

T. Rossetto

t.rossetto@ucl.ac.uk

1 Earthquake and People Interaction Centre (EPICentre), Department of Civil, Environmental and Geomatic Engineering, University College London, London, UK

2 Department of Civil and Natural Resources Engineering, University of Canterbury, Christchurch, New Zealand 
to the approximations of the geospatial analysis. Along with hazard intensity, insulation material is identified as a critical factor influencing cable fragility, with paper-insulated lead covered armoured cables experiencing considerably higher repair rates than crosslinked polyethylene cables. The analysis shows no trend between cable age and repair rates and the differences in repair rates between conducting materials is shown not to be significant. In addition to repair rate functions, an example of a fragility curve suite for cables is presented, which may be more useful for analysis of network connectivity where cable functionality is of more interest than the number of repairs. These functions are one of the first to be produced for the prediction of damage to buried cables.

Keywords Lifelines - Repair rates · Fragility functions · Buried cables · Electric power network

\section{Introduction}

When considering the potential or observed impacts of earthquakes, the predominant focus within the engineering community is towards building damage, because of its potential for casualties. Less consideration is instead given to the impacts of the earthquake on critical infrastructure systems. Although not as important as building damage for immediate life safety, the impacts on infrastructure can be significant during the emergency phase, causing delays to repair work and impeding emergency services operations. In the later recovery phase, sustained disruption to infrastructure services can slow down reconstruction and have implications for business continuity and the health and wellbeing of local residents. An effective disaster management strategy is therefore characterised by detailed assessment of the seismic safety of infrastructure networks, the assessment of the most important infrastructure component and subsequent prioritisation of mitigation works to enhance the infrastructure network resilience to potential hazards.

As discussed by Nuti et al. (2010), network safety assessment requires the analysis of a large part of the network to ensure that the interactions between components, and where applicable across networks, are considered. The general procedure is broadly similar for different types of infrastructure networks and involves the modelling of seismic actions; assessment of the structural fragility of network components; determination of the damage state of network components; construction and solution of network flow equations; and evaluation of the ability of the network to meet its customer demand. One of the key elements of such an analysis are the component fragility functions. Fragility functions estimate the likelihood of damage given a specified level of intensity measure (IM), and are the most common tools adopted for characterizing the robustness of infrastructure elements with respect to earthquake hazards (NIBS 2003; Cavalieri et al. 2014a). Whilst numerous fragility functions exist for predicting damage to buildings, fewer fragility functions exist for infrastructure systems. This is partly due to the lack of publicly available observational data of infrastructure performance on which to base empirical fragility functions.

Urban electric power networks are particularly important amongst critical infrastructure. As well as the direct consequences to consumers that may result from power outages, many other infrastructure systems also rely on power supply for their operation, including water systems that require power for pumps and hospitals that require power for essential equipment. However, electric power networks are often amongst the least reliable of 
lifelines in earthquakes. This is in part due to much of the infrastructure being constructed prior to earthquake engineering becoming common practice, but also due to conflict between the optimal configuration of network components for electrical performance and that for structural performance (Nuti et al. 2007). Despite their critical importance, there is still limited quantitative understanding of the robustness of power system components. Whilst previous studies on the seismic vulnerability of power system components exist, the risk to conduits (buried cables and overhead lines) is often neglected under the assumption that these are vulnerable only to ground deformation and not to ground shaking (e.g. Fujisaki et al. 2014). Vanzi (1996) and Hwang and Huo (1998) only consider the fragility of substations. The SYNER-G project (Cavalieri et al. 2014b) proposes a methodology for assessing the overall performance of an electrical power system, but in doing so makes the assumption that conduits are not vulnerable to direct physical damage and so damage potential is limited to substations and generation plants. The HAZUS (NIBS 2003) tool does consider cables but does not model to the risk to each cable individually. Instead, cables are combined into a single entity called a 'distribution circuit'. HAZUS proposes four fragility functions for the distribution circuit representing four damage states, each defined as a percentage of the distribution circuit that is damaged. Whilst this is suitable for estimating the scale of damage and potential repair costs, the potential for measuring the performance of the whole network in terms of connectivity or service quality (serviceability) is limited with this approach since the specific location of damaged cables is undefined. The location of damaged cables is important since in any network some cables are more critical than others depending on the size of the community that feeds off the cable (service area) and whether there is any redundancy built into the network at that location. Only Park et al. (2006) specifically consider the vulnerability of conduits, by creating fragility curves based on data from the February 2001 moment magnitude $\left(\mathrm{M}_{\mathrm{W}}\right)$ 6.8 Nisqually, Washington earthquake. However, these curves do not distinguish between overhead lines and buried cables and nor do they consider any physical attributes of the conduits that may impact on fragility. Furthermore, they only relate fragility to ground shaking intensity measures and not for permanent ground deformation. During the 2010-2011 Canterbury earthquake sequence in New Zealand, significant damage to buried cables was observed, especially after the initial $\mathrm{M}_{\mathrm{W}} 7.1$ main shock on 4th September 2010 and the $\mathrm{M}_{\mathrm{W}} 6.2$ aftershock on 22nd February 2011. The initial shock was the largest event in the sequence with its epicentre near the town of Darfield, approximately $30 \mathrm{~km}$ west of Christchurch and is hereon referred to as the Darfield earthquake. The 22nd February aftershock was the most damaging event in the sequence with an epicentre $10 \mathrm{~km}$ to the southeast of the city centre and a depth of 5-6 km inducing strong ground shaking in the city itself. This event is hereon referred to as the Christchurch earthquake. A feature of both earthquakes is the high occurrence of liquefaction and lateral spreading. These occurred as a consequence of the alluvial deposits that characterize the soil conditions in the central and eastern parts of Christchurch and the presence of a high water table. The locations of the epicentres of the two earthquakes in relation to the city of Christchurch are shown in Fig. 1. A detailed treatment of the ground motion and seismic source aspects of the sequence can be found in Yamada et al. (2011) and Bradley et al. (2014).

Buried cable damage was found to be the most costly type of damage to the power system and the main reason for long outages after the February 2011 earthquake (Kwasinki et al. 2014; Kongar et al. 2015). Typical examples of the type of damage observed are shown in Fig. 2. The damage locations and extents in the city of Christchurch were fully recorded by Orion, the local electricity distribution company, and this data provides a unique opportunity for the empirical study of buried cable fragility. This paper aims to 


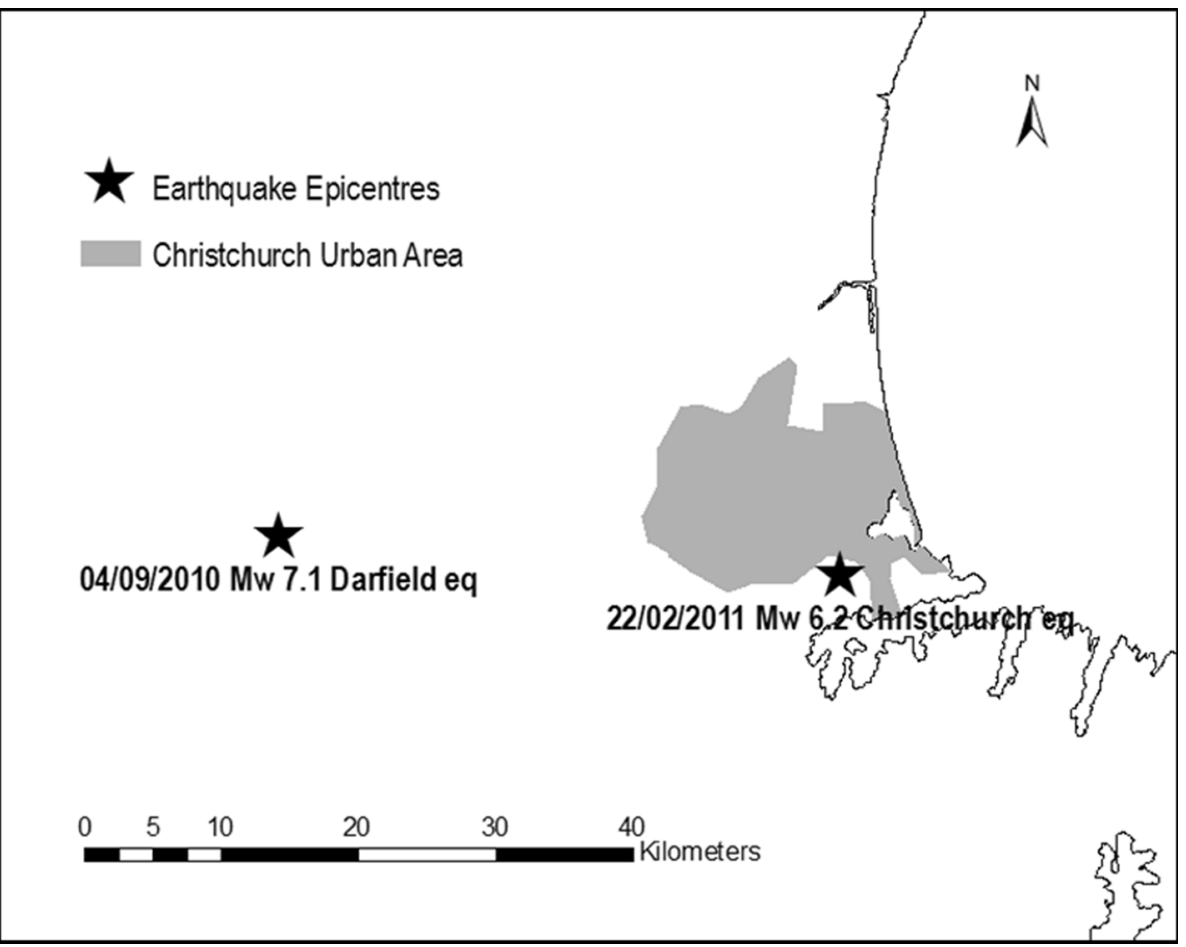

Fig. 1 Location of epicentres of the Darfield and Christchurch earthquakes in relation to the Christchurch urban area and central business district
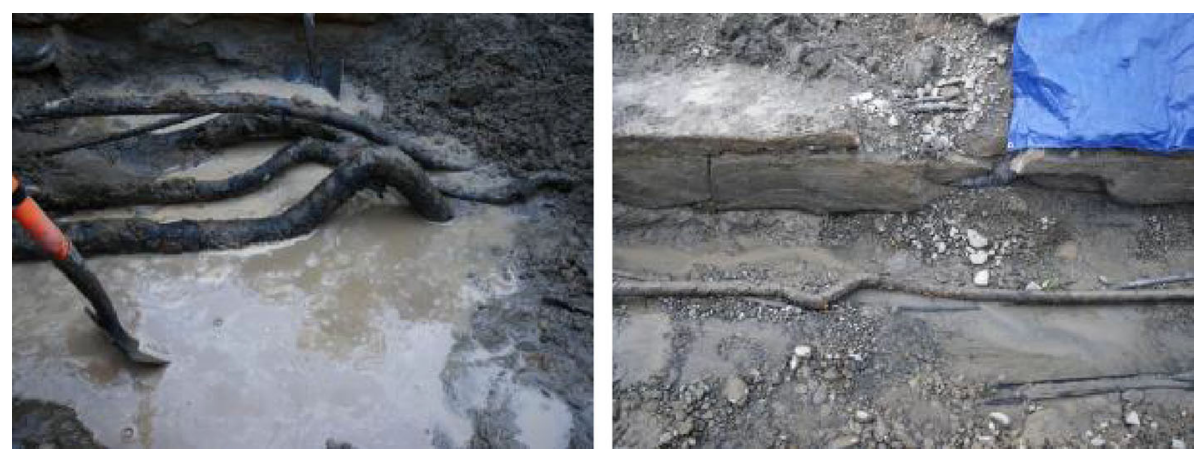

Fig. 2 Examples of typical curvature damage observed amongst buried cables due to the Canterbury earthquakes. Photos courtesy of Andrew Massie at the Christchurch Polytechnic Institute of Technology

improve understanding of the potential for earthquake-induced damage to buried cables by empirically evaluating the performance of cables in the city of Christchurch, New Zealand, during the Canterbury earthquake sequence and developing fragility functions for buried cables that can be used in future risk analyses. Since these are the first fragility functions that allow the assessment of individual cables rather than aggregated circuits, they can be useful globally for analysis of similar cable types. 
The following sections summarise the key facts about the Christchurch electric power network and observations of damage to buried cables. Repair rates for different cable typologies are analysed against a range of IMs for ground shaking and permanent ground deformation. Fragility functions are then derived for each IM by regression on the damage data, and their suitability is assessed using statistical measures. The paper concludes by recommending appropriate fragility functions for each cable typology based on the dominant hazard.

\section{Observed seismic intensities}

There are two earthquake hazards that may cause damage to buried infrastructure: transient ground deformation, which manifests itself as ground shaking, and permanent ground deformation, which may be due to liquefaction, landslides or surface rupture. This study focuses on liquefaction, which can cause either settlement (vertical permanent ground deformation) or lateral spreading (primarily horizontal permanent ground deformation but can induce a component of vertical deformation as well, Kramer 2013). In this paper, permanent ground deformation is abbreviated to PGDf, to avoid confusion with peak ground displacement (PGD). Three sets of PGDf observations are considered in this paper: two quantitative datasets from the Canterbury Geotechnical Database (CGD 2012a, b) and a qualitative dataset provided by Tonkin and Taylor, geotechnical engineering consultants to the New Zealand Earthquake Commission (EQC) (van Ballegooy et al. 2014).

The two quantitative datasets (CGD 2012a, b) are measurements of the observed vertical and horizontal ground movements using LiDAR technology. LiDAR is a technique in which a laser scanner, fires rapid pulses of laser light towards a target object and then uses a light sensor to measure the distance between the scanner and the object based on the time taken for the pulse to return, given that the speed of light is constant. When this is repeated multiple times in quick succession, a complex 3D map of the surface of the target object can be constructed. In Christchurch, airborne LiDAR systems have been used to construct digital elevation models (DEMs) of the ground surface as raster maps at a $5 \mathrm{~m}$-cell resolution (CGD 2013). The first survey took place prior to the earthquake sequence in 2003 and has subsequently been repeated after the Darfield and Christchurch earthquakes. The difference between the post-Darfield earthquake survey and the 2003 survey represents the vertical movement due to the Darfield earthquake, and similarly the difference between the post-Christchurch earthquake and the post-Darfield earthquake surveys represents the movement due to the Christchurch earthquake. In addition to liquefaction, elevation changes recorded by LiDAR include changes caused by tectonic uplift. Therefore, to evaluate the vertical movement due to liquefaction effects only, i.e. the total settlement, the differences between LiDAR surveys have been corrected to remove the effect of the tectonic movement. Figure $3^{1}$ shows the total settlements after the Darfield earthquake. It is surmised that after the Christchurch earthquake, the condition of a cable is dependent on the cumulative effects of liquefaction from both earthquakes rather than just from

\footnotetext{
${ }^{1}$ Figures 3, 4 and 5 were created from maps and/or data extracted from the Canterbury Geotechnical Database (https://canterburygeotechnicaldatabase.projectorbit.com), which were prepared and/or compiled for the Earthquake Commission (EQC) to assist in assessing insurance claims made under the Earthquake Commission Act 1993. The source maps and data were not intended for any other purpose. EQC and its engineers, Tonkin and Taylor, have no liability for any use of the maps and data or for the consequences of any person relying on them in any way. This "Important notice" must be reproduced wherever Figs. 3, 4 and 5 or any derivatives are reproduced.
} 


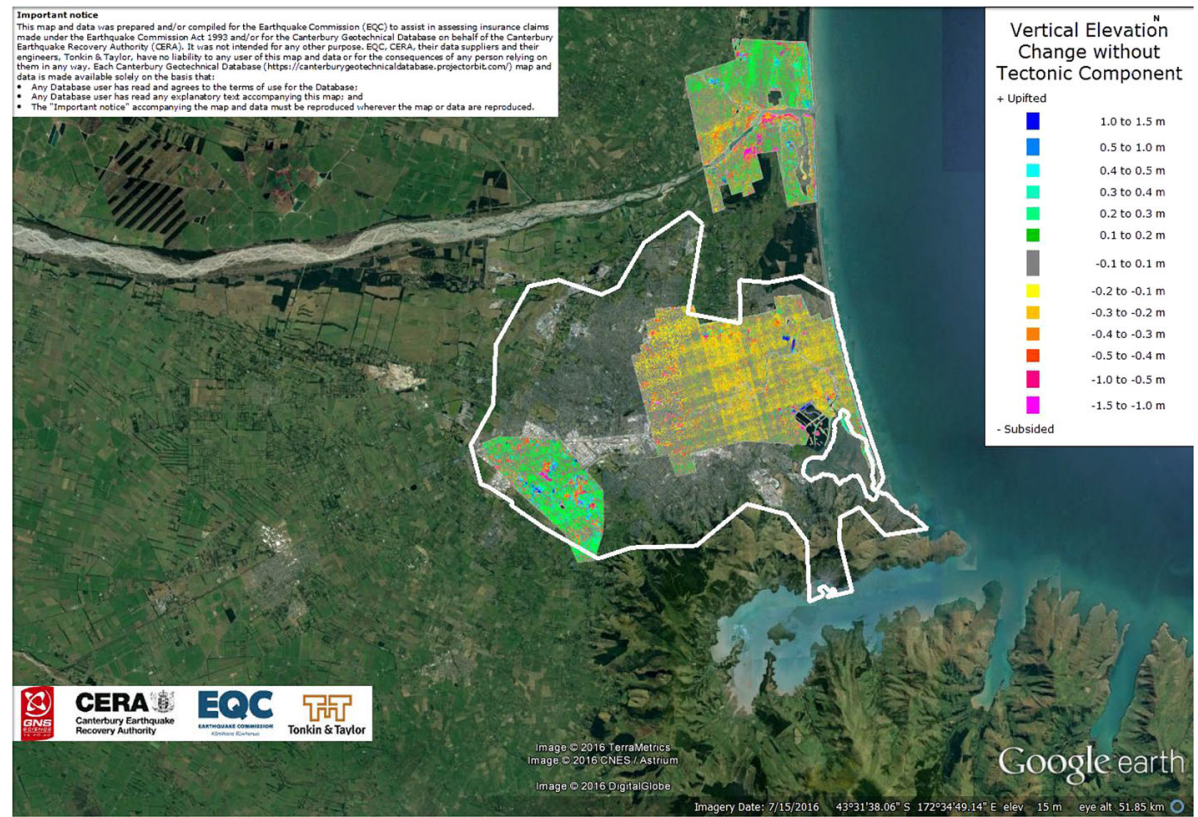

Fig. 3 LiDAR measurements of liquefaction-induced vertical settlement after the Darfield earthquake

Christchurch earthquake in isolation. Therefore Fig. 4 (see footnote 1) shows the cumulative total settlements after the Christchurch earthquake. Horizontal movements have been estimated using a pattern-matching co-registration process (Leprince et al. 2007), also known as subpixel correlation, to find the relative position of corresponding pixels across successive DEMs (van Ballegooy et al. 2014). Figure 5 (see footnote 1) shows the horizontal movement after the Darfield earthquake and the cumulative horizontal movement after both the Darfield and Christchurch earthquakes.

However, the LiDAR method for measuring ground deformations has some shortcomings. Metadata provided by the LiDAR contractor indicates accuracy of up to $\pm 0.07 \mathrm{~m}$ in the vertical direction and up to $\pm 0.4 \mathrm{~m}$ in the horizontal direction. To put this into context, the range of measured ground movements is up to $\pm 1.5 \mathrm{~m}$ in the vertical direction and up to $3.2 \mathrm{~m}$ in horizontal direction. Furthermore, the pre-earthquake LiDAR survey took place seven years prior to the Darfield earthquake. Without intermediate surveys to identify and reconcile potential changes to elevation and position that may have occurred during the intervening period, it is assumed that all changes identified by the post-Darfield earthquake survey are due to liquefaction effects in that event. These shortcomings mean that the LiDAR analysis may not be estimating the magnitude of deformations with high precision. However, this LiDAR dataset has been used previously to derive empirical repair rate functions for pipelines (O'Rourke et al. 2014) and in the absence of any alternative quantitative ground deformation data, it is used for the analysis in this paper.

An effect of the imprecision of the LiDAR surveys is that it may yield false positive observations of liquefaction, i.e. measuring ground movements in locations where no liquefaction occurred. It is therefore proposed to validate the LiDAR dataset with a qualitative dataset of liquefaction observations based on post-earthquake on-the-ground surveys and aerial photography. Tonkin and Taylor have provided a GIS dataset 


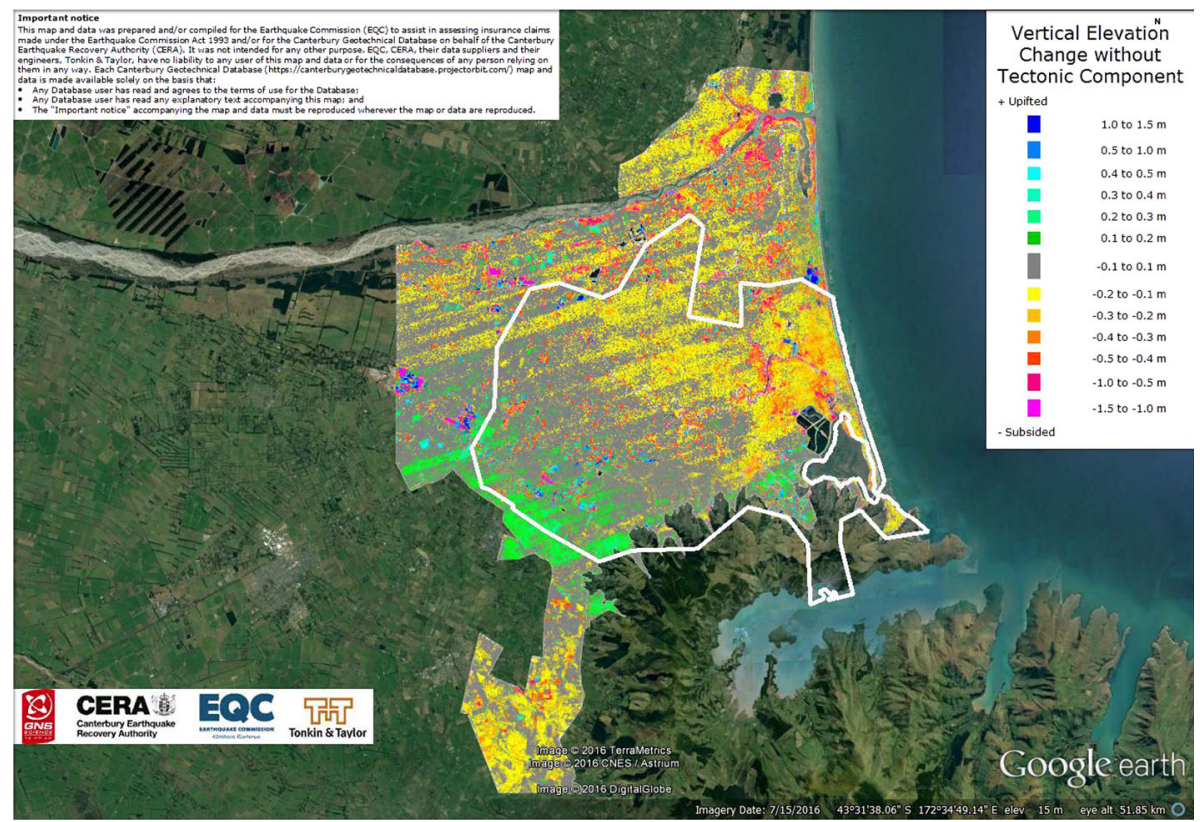

Fig. 4 LiDAR measurements of cumulative liquefaction-induced vertical settlement after the Darfield and Christchurch earthquakes

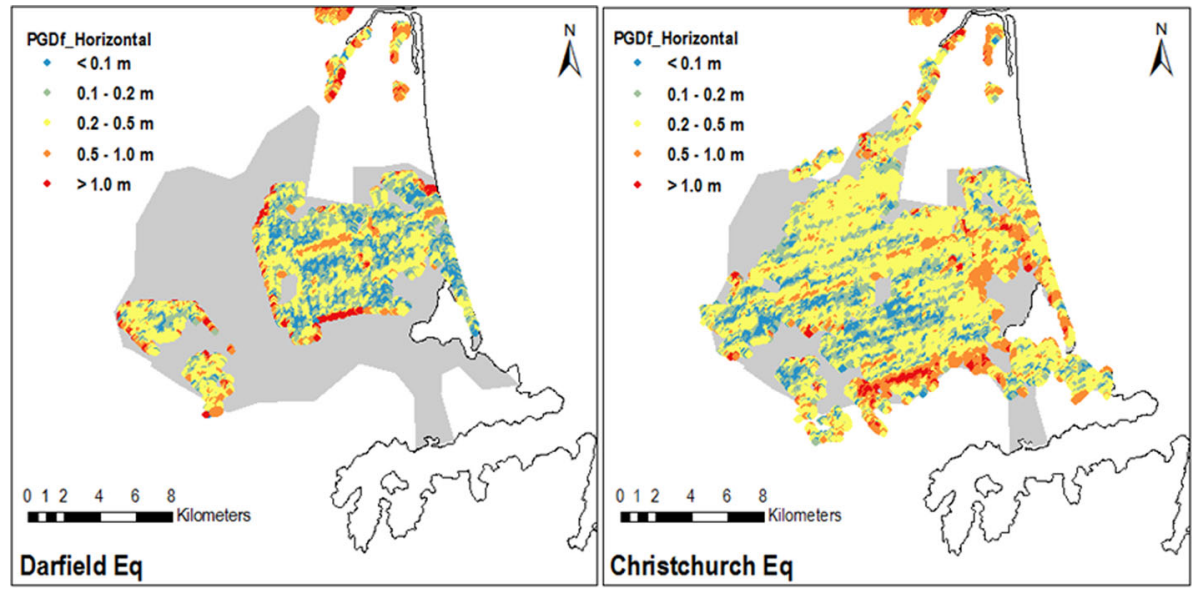

Fig. 5 Maps of horizontal ground movements $\left(\mathrm{PGDf}_{\mathrm{H}}\right)$ after the Darfield earthquake and cumulatively after the Christchurch earthquake from LiDAR surveys. The maps have been reproduced from data from the Canterbury Geotechnical Database

representing 70,000 borehole locations, with attribute information describing the qualitative surface land damage category at each location for both earthquakes. There are six land damage categories, which are listed and described in Table 1. Land damage category 2 is described by Tonkin and Taylor as 'minor ground cracking', reflecting the fact that no 
liquefaction ejecta material is observed on the surface. However, even when no ejecta material is observed, ground cracking can be interpreted as evidence of liquefaction in deeper soil layers and in subsequent studies of liquefaction in the Canterbury earthquake sequence, this category is described as either 'liquefaction, certain' (Brackley, 2012), which is defined as being greatly affected by liquefaction, or 'marginal liquefaction' (Green et al. 2014; Maurer et al. 2014). Almost all observation of category 2 are in very close proximity to observations from categories 3-6 and so for the purposes of this analysis, category 2 is assumed to represent the occurrence of liquefaction. To validate the LiDAR measurements, four observed liquefaction 'zones' are defined, based on the land damage categories as shown in Table 1 .

The four zones are: (A) no liquefaction (category 1); (B) observed liquefaction (categories 2-6); C) observed liquefaction with settlement only (categories 3 and 4); and D) observed liquefaction with lateral spreading (categories 2, 5 and 6). The zones are not exclusive since zones $\mathrm{C}$ and $\mathrm{D}$ are sub-divisions of zone $\mathrm{B}$. The motivation of this paper is to analyse the vulnerability of buried cables with respect to different seismic hazards and the separation of data into zones helps to ensure that the datasets for each type of hazard only include cables that are relevant to that particular hazard. The criteria for inclusion in zone $\mathrm{D}$ is that the cable is in an area where there is a LiDAR measurement of horizontal movement and this measurement is validated by an on-the-ground observation of lateral spreading. The criteria for inclusion in zone $\mathrm{C}$ is that the cable is an area where there is a LiDAR measurement of vertical movement and this measurement is validated by an onthe-ground observation of settlement. All other cables are included in zone A.

The extents of each zone are extrapolated from the borehole samples by Thiessen polygons (de Smith et al. 2009), which is a type of nearest neighbour analysis. In the Thiessen polygon method, discrete sampled point observations of a variable can be extrapolated to a surface of discrete zones by assigning locations in the unsampled space with the attributes of the closest sample point. For example, if the closest sample point to an unsampled location is observed to be land damage category 4 , then the unsampled location is assumed to be in land damage category 4 also. This procedure for creating liquefaction zones also exhibits shortcomings however. The extrapolation of attributes from sampled points into unsampled space means that at some locations the observed liquefaction zone may be misclassified. Also the land damage categories at each sample point only represent evidence of liquefaction at surface-level and so may yield false negative observations in places where liquefaction has occurred but only below the surface. Although neither the LiDAR data nor the surface observation data provide are able to

Table 1 Land damage categories in data provided by Tonkin and Taylor for qualitative liquefaction observations

\begin{tabular}{llllll}
\hline Land damage category & Description & Zone A & Zone B & Zone C & Zone D \\
\hline 1 & No liquefaction & Yes & No & No & No \\
2 & Minor ground cracking & No & Yes & No & Yes \\
3 & Liquefaction-moderate settlement only & No & Yes & Yes & No \\
4 & Liquefaction-severe settlement only & No & Yes & Yes & No \\
5 & Liquefaction-moderate lateral & No & Yes & No & Yes \\
& spreading & & & & \\
6 & Liquefaction-severe lateral spreading & No & Yes & No & Yes \\
\hline
\end{tabular}


provide a precise record of where liquefaction occurred, the proposal to make use of information from both datasets will help to validate the observations and make the repair rate function derivation more robust, particularly for the functions relating to vulnerability to liquefaction. Figure 6 shows the extrapolated map of qualitative surface liquefaction observations accumulated into the three independent zones, A, C and D (zone B representing the coalition of zones $\mathrm{C}$ and $\mathrm{D}$ ).

There are a number of intensity measures that can be used to evaluate ground shaking but it is assumed that peak ground velocity (PGV) is the most relevant to buried infrastructure since it relates to ground strain (Pineda-Porras and Najafi 2010). PGV has also been shown in the literature to be well-correlated with damage to pipelines (Isoyama et al. 2000; O'Rourke et al. 2001). Whilst in some areas of Christchurch ground shaking was the only observed hazard, in other areas both ground shaking and permanent ground deformation were observed. Kwasinki et al. (2014) conclude that the peak ground velocities observed during the Canterbury earthquakes were not sufficiently large to cause strains in $66 \mathrm{kV}$ cables that would induce failure. Therefore, for this analysis it is assumed that ground deformation is the predominant hazard (O'Rourke et al. 2014), and PGV is only expected to be a factor in areas where liquefaction was not observed. Maps of the maximum horizontal PGV for the two earthquakes are shown in Fig. 7 and are based on data from the US Geological Survey ShakeMap (USGS 2015a, b).

The use of ShakeMaps to estimate observed ground motions has some limitations, given that they are generated automatically within several minutes of an earthquake. ShakeMaps take observations from seismic stations and then interpolate using ground motion prediction equations to estimate the ground motion elsewhere. In total 125 stations are used to constrain the ShakeMaps for both earthquakes, although only 14 of these, shown in Fig. 8, are located in Christchurch itself. The error in estimation of interpolated ground motions increases with distance from seismic stations. The USGS reports the error of a ShakeMap estimate at a point as a multiplicative scaling factor to be applied to the error of the underlying ground motion prediction equation. The ShakeMaps only report the mean of the scaling factors reported for peak ground acceleration (PGA) estimates but Wald et al. (2008) state that factors reported for PGA can be applied directly to PGV also. The mean

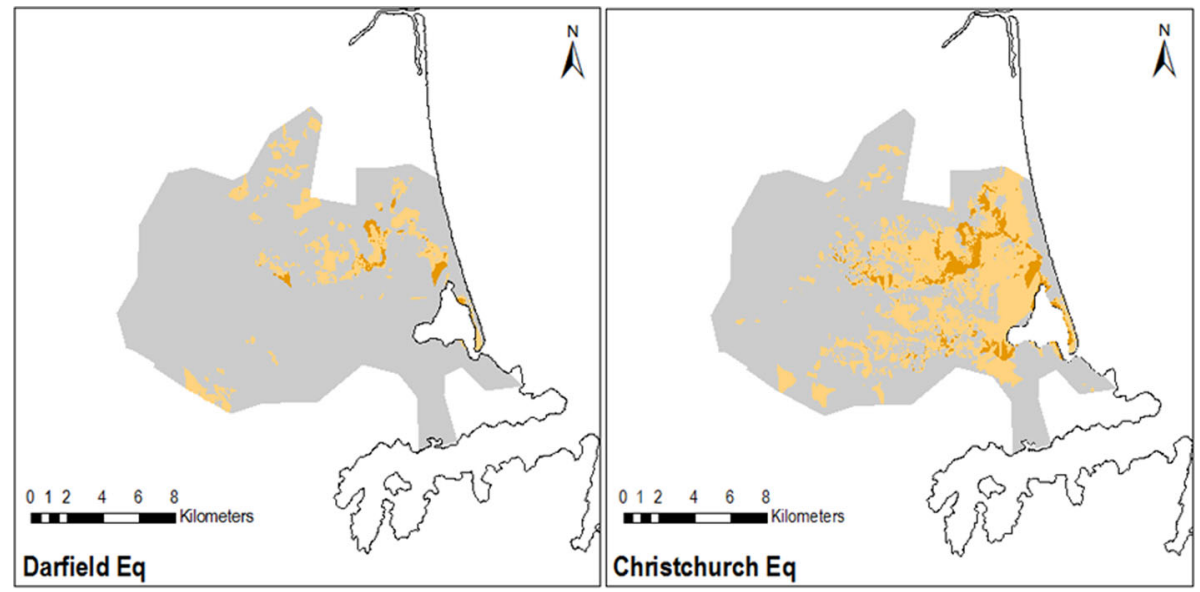

Fig. 6 Surface liquefaction observations in the Christchurch urban area due to the Darfield and Christchurch earthquakes based on sample data collected by Tonkin and Taylor. The maps indicate areas of no liquefaction (grey), vertical settlement (orange) and lateral spreading (brown) 


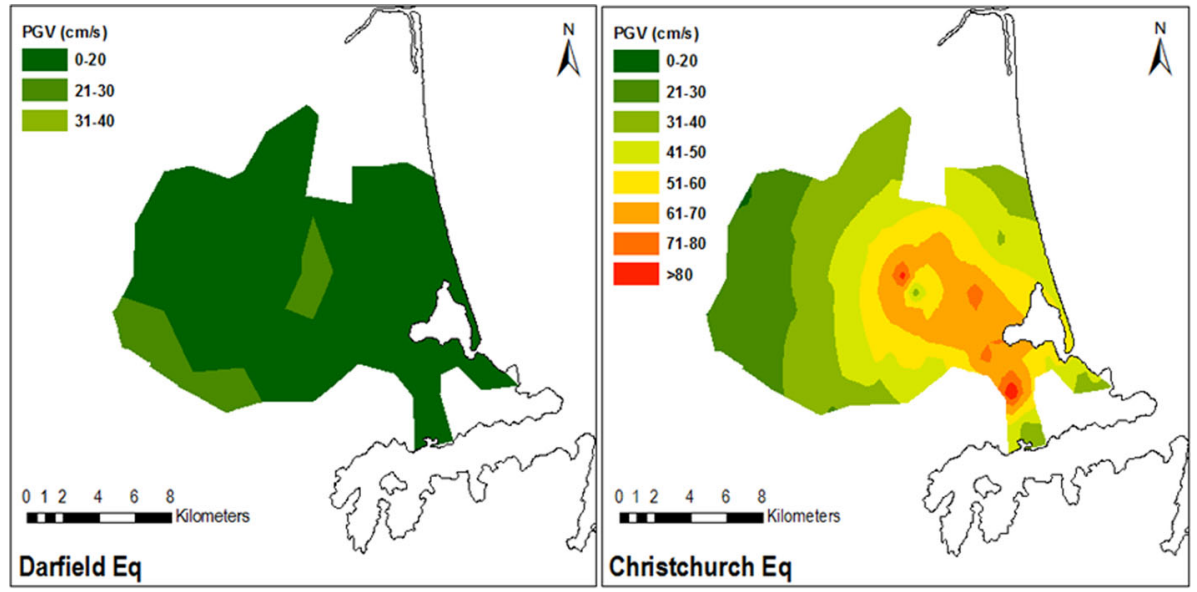

Fig. 7 Peak ground velocity (PGV) maps for the Christchurch urban area from the Darfield and Christchurch earthquakes, based on data from the US Geological Survey

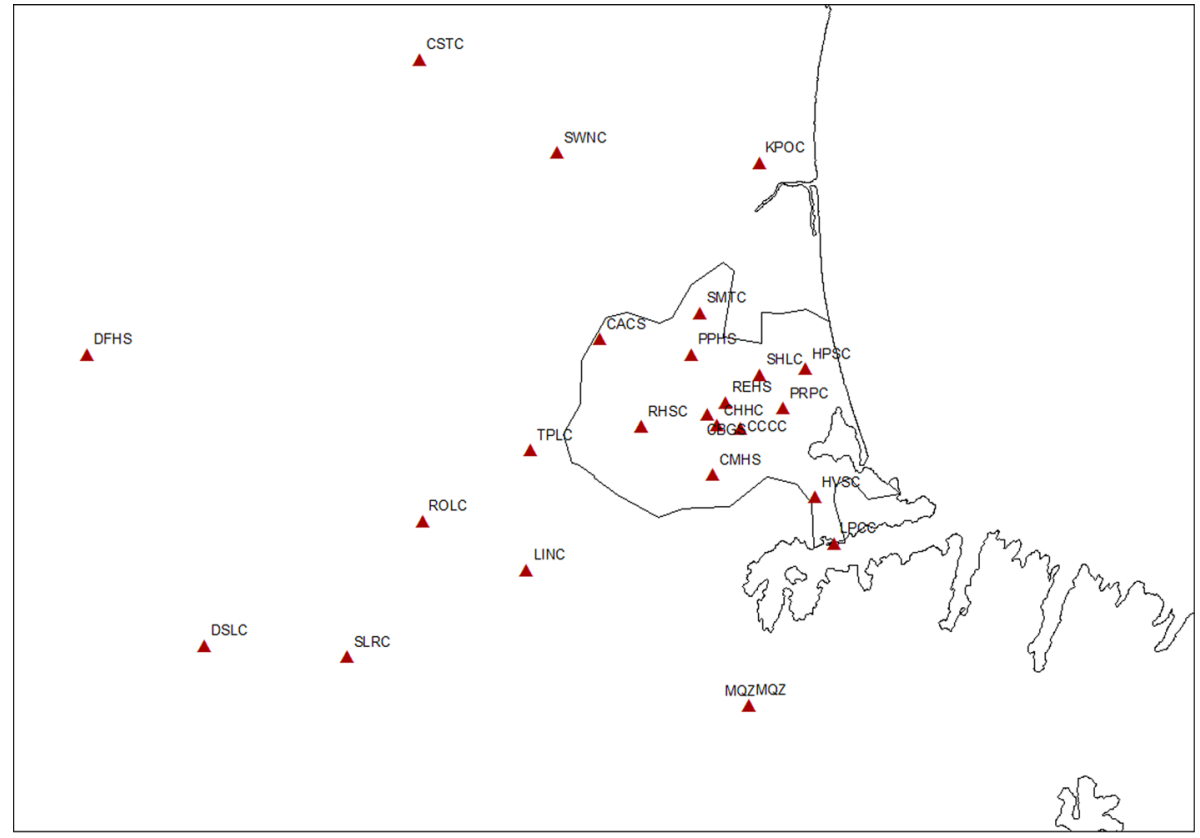

Fig. 8 Location of seismic stations (red triangles) from which recordings were used to generate USGS ShakeMaps

reported for the Darfield earthquake is 0.705 and the mean reported for the Christchurch earthquake is 0.507 . Both maps are rated as Grade A for quality based on uncertainty, which places them amongst the highest quality maps that ShakeMap produces and reflects the fact that these ShakeMaps are based on fault and moment tensor information as well as station observations. Since Christchurch is located in a shallow crustal tectonic 
environment, PGA and spectral accelerations (SA) are interpolated using the ground motion prediction equation of Boore et al. (1997), while PGV is assumed to be proportional to the $1.0 \mathrm{~s}$ PSA, according to the relationship of Newmark and Hall (1982). Boore et al. (1997) report the standard error of the natural logarithm of $1.0 \mathrm{~s}$ PSA predictions as 0.569 , but application of the scaling factor reduces this to 0.401 for the Darfield earthquake and 0.288 for the Christchurch earthquake. In terms of natural scales, these errors convert to error ranges for 1.0 s PSA predictions of 0.67-1.49 times the median predictions for the Darfield earthquake and $0.75-1.33$ times the median predictions for the Christchurch earthquake. Since PGV is assumed to be proportional to the $1.0 \mathrm{~s}$ PSA, the same error range can be applied to PGV. It is not unusual for repair rate functions for pipelines to be based directly on ground motion maps generated by interpolation from station observations (e.g. Toprak and Taskin 2006; Esposito et al. 2013; O'Rourke et al. 2014) and estimated ground motion errors are not often reported in these cases so it is difficult to make a comparison. Therefore, in the absence of more reliable PGV mapping for both earthquakes, the ShakeMaps are used for the analysis in this paper.

\section{Christchurch electric power network}

Transpower is the national supplier of electric power in New Zealand, transmitting power along high voltage lines from generating sites to demand centres, where it is further transmitted and distributed by local suppliers to customers. Orion is the local distribution company for Christchurch and they receive power from Transpower at five grid exit points, where the power is transformed from $220 \mathrm{kV}$ down to medium voltages (11-66 kV). There are four levels in the Orion network hierarchy: sub-transmission at 66 or $33 \mathrm{kV}, 11 \mathrm{kV}$ primary distribution, $11 \mathrm{kV}$ secondary distribution and $400 \mathrm{~V}$ distribution. This paper focuses on the $11 \mathrm{kV}$ primary and secondary distribution networks since this is the portion for which damage data has been made available. Whilst cables at the sub-transmission level are arguably more important, since they feed into the $11 \mathrm{kV}$ network, 66 and $33 \mathrm{kV}$ cables make up less than 3\% of cables by length in Christchurch (Orion 2009). In terms of overall failure rates, $5.5 \%$ of $11 \mathrm{kV}$ cables suffered a failure in the Christchurch earthquake compared to just $0.6 \%$ of $400 \mathrm{~V}$ cables (Kwasinki et al. 2014). Therefore, studying the $11 \mathrm{kV}$ network provides sufficiently large exposure and failure datasets from which to draw conclusions on buried cable performance. Information on the locations, attributes and damage observations of cables has been provided by Orion. However, due to commercial sensitivity some information has necessarily been withheld here. In Fig. 9 the locations of the $11 \mathrm{kV}$ cables are mapped over the areas of observed surface liquefaction for each earthquake, as defined by Tonkin and Taylor. Although the analysis in this paper includes all cables in the Christchurch City Council (CCC) area, for clarity Fig. 9 is zoomed in on the urban area of Christchurch.

The primary attribute used to classify cable typologies is the insulation material. The insulation provides the structure to a cable that is susceptible to ground movements (Orion, personal communication). In Christchurch three materials are used for $11 \mathrm{kV}$ cable insulation: paper-insulated lead covered armoured (PILCA), cross-linked polyethylene (XLPE) and a small number of PILCA cables reinforced with high-density polyethylene (PILCA HDPE). Prior to the Darfield earthquake there was $1945 \mathrm{~km}$ of underground cable in the $11 \mathrm{kV}$ distribution network in the CCC area, made up of over 11,500 individual cables. This includes $1491 \mathrm{~km}$ of PILCA cable, $380 \mathrm{~km}$ of XLPE cable, and $59 \mathrm{~km}$ of PILCA 


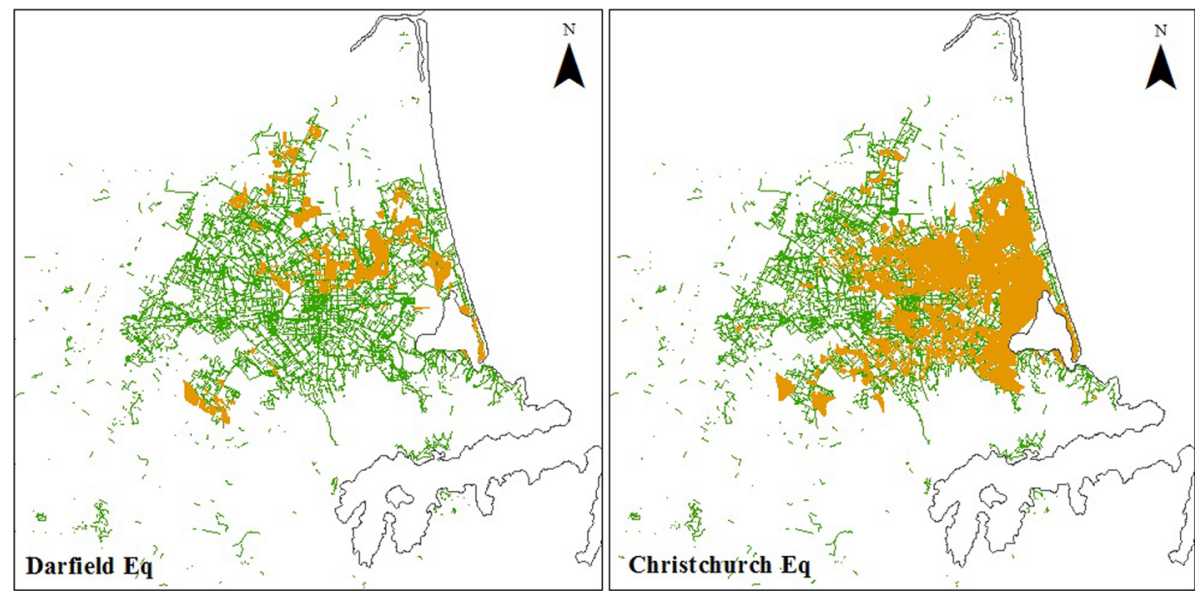

Fig. 9 Orion $11 \mathrm{kV}$ buried cables in the Christchurch urban area mapped over surface liquefaction observations from Tonkin and Taylor

HDPE cable, with the remainder unknown. The locations of observed cable repairs due to each earthquake are shown in Fig. 10. 24 buried cable repairs were undertaken after the Darfield earthquake and a further 433 after the Christchurch earthquake, predominantly amongst PILCA cables. It is noted that the number of repairs does not necessarily translate into the number of observed faults, since in cases where faults occurred close together on a cable, the section of cable was replaced with a single repair and recorded as such. There are no records describing the number of faults that relate to each repair and this may explain the discrepancy (Orion personal communication) between the data used in this study and the information presented previously by others, such as Eidinger and Tang (2012) and Kwasinki et al. (2014). The other attribute that may be of importance is the material used for the conducting core. However, Kwasinki et al. (2014) observe that the conducting materials used in Christchurch (copper and aluminium) should be able to accommodate the

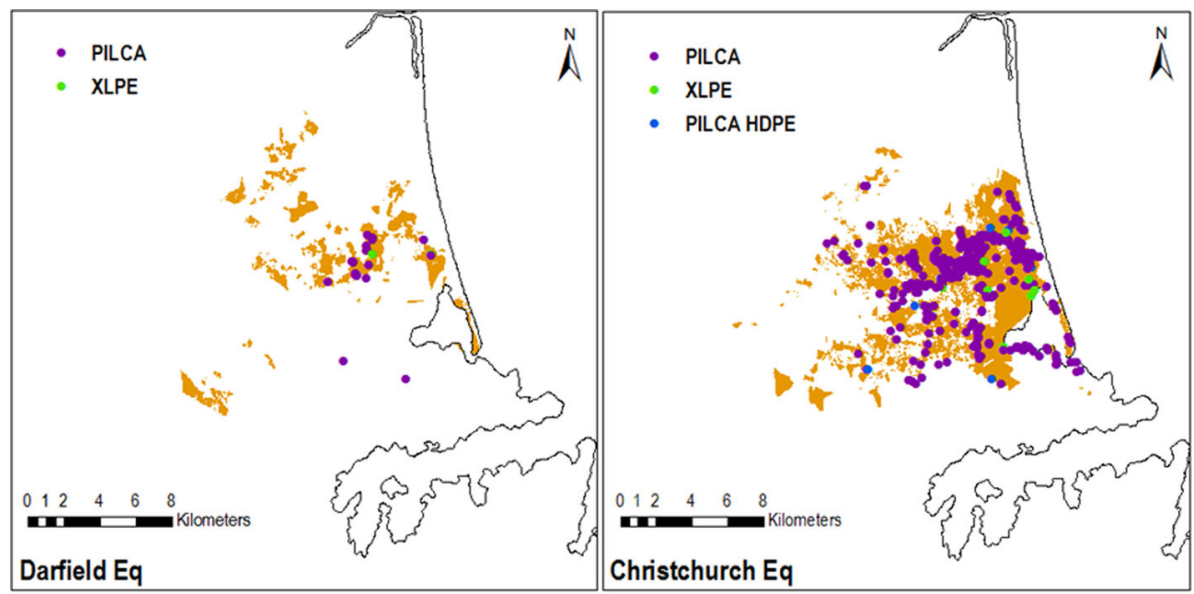

Fig. 10 Locations of recorded buried $11 \mathrm{kV}$ cable repairs due to each earthquake by insulation material 
moderate extension that could be expected due to liquefaction. Therefore cable faulting is more likely to be caused by yielding of the outer insulation layer. Nevertheless, the influence of conducting material on cable fragility is considered in this paper.

\section{Methodology}

\subsection{Proposed IMs}

This study proposes repair rate functions for buried cables for six IMs. These include maximum horizontal PGV for ground shaking, $\mathrm{PGDf}_{\mathrm{V}}$ for vertical ground deformation and $\mathrm{PGDf}_{\mathrm{H}}$ for horizontal ground deformation. In this paper, $\mathrm{PGDf}_{\mathrm{V}}$ is defined as the differential vertical settlement imposed on a cable, which is distinct from the total vertical settlement shown in Figs. 3 and 4. For each $5 \mathrm{~m}$-cell in the LiDAR raster map, the difference in total settlement is calculated eight times, by subtracting the total settlement of the cell from the total settlement of each cell surrounding it. The differential settlement is then estimated as the maximum of these eight differences in total settlement. Additionally, three IMs are proposed that combine the effect of horizontal and vertical ground deformation: $\mathrm{PGDf}_{\mathrm{MAX}}$, which is the maximum of $\mathrm{PGDf}_{\mathrm{V}}$ and $\mathrm{PGDf}_{\mathrm{H}}$; $\mathrm{PGDf}_{\mathrm{VECT}}$, which is the vector mean of $\mathrm{PGDf}_{\mathrm{V}}$ and $\mathrm{PGDf}_{\mathrm{H}}$; and $\mathrm{PGDf}_{\mathrm{GEOM}}$, which is the geometric mean of $\mathrm{PGDf}_{\mathrm{V}}$ and $\mathrm{PGDf}_{\mathrm{H}}$. The primary purpose of these three combined IMs is to provide a more detailed analysis in areas where lateral spreading occurred, since lateral spreading can induce both horizontal and vertical movements. It is also of interest to assess whether the combined effect may relate better to cable damage. The specific combinations have not been selected for any known physical relationship. All three methods are however commonly applied to the measurement of ground shaking intensity (ALA 2001; Toprak and Taskin 2006; Akkar and Bommer 2007), which is usually recorded at a station in three orthogonal directions before being reported as a single composite value. The formulae for the combined effect IMs are shown in Eq's (3 to 5).

$$
\begin{gathered}
P G D f_{M A X}=\max \left\{P G D f_{H}, P G D f_{V}\right\} \\
P G D f_{V E C T}=\sqrt{P G D f_{H}^{2}+P G D f_{V}^{2}} \\
P G D f_{G E O M}=\sqrt{P G D f_{H} \times P G D f_{V}}
\end{gathered}
$$

It is anticipated that in liquefaction zone $\mathrm{A}$, where no surface liquefaction was observed to occur, only PGV should provide meaningful results. In liquefaction zone $\mathrm{C}$, which covers observed settlement, only PGDf $_{\mathrm{V}}$ should be relevant. In liquefaction zone B, which covers all liquefaction, and in liquefaction zone $\mathrm{D}$, which covers lateral spreading, all the IMs except PGV may provide meaningful results. Despite this however, given the uncertainty in both the quantitative and qualitative liquefaction observations described in Sect. 2, repair rate analysis is conducted in each zone for all IMs to highlight any unexpected trends that may arise from the data.

\subsection{IM assignment}

The observed ground deformation data used in this analysis is at a high resolution $-5 \mathrm{~m}$ for vertical and $56 \mathrm{~m}$ for horizontal—and so when assigning IM values to cables, it is 
observed that most are exposed to more than one value of $\operatorname{PGDf}_{\mathrm{V}}$ and $\operatorname{PGDf}_{\mathrm{H}}$. There are different ways that this can be addressed to assume a single value for the entire cable, e.g. maximum, mean, median, mode or another statistical permutation of each value observed along its length. For relatively short cables, such an approximation may have little influence on the calculations, but for longer cables-some cables are in excess of $1 \mathrm{~km}$ and so would have over 200 separate $\mathrm{PGDf}_{\mathrm{V}}$ observations - there may be significant implications. In particular, exposures to very low and very high values of PGDf may be underestimated due to the averaging process, which in turn could lead to conservative estimates of repair rates at these values. Conversely, exposures to moderate values of PGDf may be overestimated, leading to an underestimation of repair rates. An alternative is to discretise the cables according to the PGV contours and/or PGDf raster cells (e.g. ALA 2001; PinedaPorras and Ordaz 2010; Wang 2013). This approach allows more precise IM data to be captured in the measurements of exposure, resulting in more reliable repair rates. Discretisation is therefore adopted in this analysis, with cables split into $5 \mathrm{~m}$ segments to match the resolution of the most precise IM dataset, PGDf $_{\mathrm{V}}$. Each segment is assigned the $\mathrm{PGV}$ value from the closest contour, and the $\mathrm{PGDf}_{\mathrm{V}}$ and $\mathrm{PGDf}_{\mathrm{H}}$ values from the raster cell in which it is located.

\subsection{Repair rate function derivation}

In guidance published by the American Lifelines Alliance (ALA 2001) for pipelines, two potential forms of repair rate function are proposed: A linear repair rate function, as shown in Eq. (6), and a power relationship as shown in Eq. (7), where $R R$ is the repair rate and $I M$ is the intensity measure. If Eq. (7) is re-written to make the constant multiplier an exponential term, as shown in Eq. (8), then by taking the natural logarithm of both sides, the power relationship function can also be expressed in linear form, as shown in Eq. (9).

$$
\begin{gathered}
R R=a \cdot I M \\
R R=b \cdot I M^{c} \\
R R=\exp ^{d} \cdot I M^{c} \\
\ln R R=c \cdot \ln I M+d
\end{gathered}
$$

For a particular cable typology and IM, the repair rate at each IM level is calculated as the number of observed repairs per kilometre of exposure at that IM level. A repair rate function, of the form of Eq. (6) or (9), is then generated by performing a linear regression on the series of RR versus IM data points. The method for estimating the repair rates differs for each IM. For PGV, repair rates are only estimated for the Christchurch earthquake since the number of repairs observed in the Darfield earthquake is too small to produce meaningful repair rates. Each cable is assigned a PGV value as described in Sect. 4.3 and classified into a liquefaction analysis zone based on the Tonkin and Taylor observations. For each zone and PGV value combination, the total length of cable exposed and number of repairs is evaluated. The repair rate is then given by Eq. (10).

$$
R R(P G V \mid \text { Zone })=\frac{\text { Repairs }\left(P G V \mid \text { Zone }_{\text {CHRISTCHURCH }}\right.}{\text { Length }(P G V \mid \text { Zone })_{\text {CHRISTCHURCH }}}
$$

However for liquefaction, the effects of the two earthquakes are cumulative and therefore the values of $\mathrm{PGDf}_{\mathrm{V}}$ and $\mathrm{PGDf}_{\mathrm{H}}$ experienced by a cable in the Christchurch earthquake are 
not independent of the values of $\mathrm{PGDf}_{\mathrm{V}}$ and $\mathrm{PGDf}_{\mathrm{H}}$ experienced in the earlier Darfield earthquake. Therefore, for PGDf repair rates, the assignment of IM value and liquefaction zone more complex. For cables damaged in the Darfield earthquake, the assigned IM value and liquefaction zone is simply the observation from that event. For other cables, the assigned IM value is the cumulative deformation after the Christchurch earthquake and liquefaction zones are assigned based on a hierarchy. A cable is classified as being in zone $\mathrm{D}$ (and by extension zone $\mathrm{B}$ ) if it is located in an area where lateral spreading was observed in either event. A cables is classified as being in zone C (and zone B) if it is located in area where settlement was observed in either event but no lateral spreading was observed. All other cables are classified as being in zone A. For a given zone and PGDf combination, the repair rate is the number of repairs observed divided by the total cable length exposed. When deriving repair rate functions for pipelines from the Canterbury earthquakes, O'Rourke et al. (2012) use a screening criterion to determine which repair rate data points should be included in the regression, since some may be unreliable due to being based on a small number of faults or small measured area. The principle of the criterion is to calculate the observed repair rate and subsequently determine what is the minimum total cable length required to be statistically confident in the reliability of the repair rate-defined by the authors as a probability of 0.94 of observing at least two repairs if the distance interval between repairs is assumed to follow a Poisson distribution (Hwang et al. 1998, Adachi and Ellingwood, 2008). The smaller the observed repair rate, the larger the exposure length needs to be. If the exposure on which a repair rate is calculated is below the minimum length, the data point is excluded from the analysis. The formula for the minimum length $\left(\mathrm{x}_{\mathrm{min}}\right)$ is shown in Eq. (11).

$$
x_{\min }=-\ln (0.01) / R R
$$

Additional screening criteria are applied to the repair rate observations, including an absolute minimum exposure of $1 \mathrm{~km}$ (O'Rourke et al. 2012), in order to limit the influence of potentially unusual localised conditions that only affect small lengths of cable. Furthermore, a minimum of two observed repairs per IM value is included as a condition, since the objective is to calculate a rate. Due to these criteria and the need to ensure that each repair rate observation is based on a sufficient number of faults and total cable length, the regression is performed on the observed repair rates across IM bins rather than for unique IM values. The bin width for PGV is $5 \mathrm{~cm} / \mathrm{s}$ and the bin width for PGDf is either $0.05 \mathrm{~m}$ or $0.1 \mathrm{~m}$, with the width selected in order to maximise the number of data points that meet the screening criteria. In order to provide a measure of the uncertainty of each repair rate observation, $95 \%$ confidence intervals are calculated by adapting the method of Ulm (1990) and Dobson et al. (1991) for confidence intervals around a Poisson mean as shown in Eq. (12) and (13), where $E$ is the exposure in kilometres and $r$ is the number of observed repairs. This confidence interval is therefore a function of exposure length (the greater the exposure, the smaller the confidence interval) and is displayed on each plot in 10 by error bars around each observation point.

$$
\begin{gathered}
R R_{\text {obs_low }}=\frac{\left(\chi_{0.975,2 \cdot r}^{2}\right)}{2 \cdot E} \\
R R_{\text {obs_upp }}=\frac{\left(\chi_{0.025,2(r+1)}^{2}\right)}{2 \cdot E}
\end{gathered}
$$


Another source of uncertainty is in the regression procedure itself. Hence, the $95 \%$ confidence interval is presented for all the lines of best fit. The confidence interval, $C I_{i}$, at an IM value, $x_{i}$, is given by the formula in Eq. (14), where $R R_{i}$ is the mean estimate of the repair rate from the fitted regression model at $x_{i}, \bar{x}$ is the mean of the observed IM values used in the regression, $n$ is the number of observations used in the regression, $S_{y x}$ is the standard error of the repair rate estimates from the regression and $t$ is the critical t-statistic with $n$-2 degrees of freedom $(d f)$ and $\alpha=0.05$.

$$
C I_{i}=R R_{i} \pm t(\alpha, d f) S_{y x} \sqrt{\frac{1}{n}+\frac{\left(x_{i}-\bar{x}\right)^{2}}{\sum_{i=1}^{n}\left(x_{i}-\bar{x}\right)^{2}}} .
$$

\section{Repair rate analysis}

\subsection{Analysis zones}

Repair rate analysis is conducted for the four liquefaction 'zones' summarised in Table 1. In each zone, all proposed IMs are analysed. Table 2 summarises the observations in each study area for each cable insulation typology. It is important to note that the majority of cables in Christchurch are of the PILCA typology. Consequently, although the final column presents data for all typologies combined for reference, this data is strongly influenced by the PILCA typology. The following sections summarise the repair rate function derivations for each analysis zone in detail. Generally it is observed that across all cable typologies, repair rates are considerably larger in liquefied zones than in zones where ground shaking was the only observed hazard, Furthermore, repair rates in the ground shaking zone are very low. This concurs with the observations of Kwasinki et al. (2014), that the cable materials present in Christchurch should be able to accommodate the ground strains generated by the earthquakes without yielding, as well as the observations from other earthquakes that ground deformation is the primary source of damage to buried cables (Tanaka et al. 2008; Fujisaki et al. 2014). The reliability of the repair rates for XLPE and PILCA HDPE typologies in the non-liquefied zone are somewhat uncertain since they are based on a single repair observation. However, when compared to the repair rates calculated for the PILCA typology, they are of a similar order of magnitude and exhibit a similarly large reduction relative to their corresponding repair rates in the liquefaction zone. Consequently these repair rates can be considered plausible. Within the liquefaction zone, repair rates are higher in the areas where lateral spreading is observed than in the areas where only settlement is observed, indicating that movement in the horizontal plane is more damaging to cables. Finally, in general higher repair rates are observed for the PILCA typology than for XLPE or PILCA HDPE typologies. The exception is in the lateral spread zone where the repair rate for PILCA HDPE is very high, although this is based on just a $1 \mathrm{~km}$ exposure and so may be influenced by unusual local conditions.

\subsubsection{Zone A: no liquefaction}

Figure 11 shows the repair rate observations and fitted regression models for PILCA cables as a function of each of the candidate IMs. For conciseness, only the best performing (as defined by highest coefficient of determination, $\mathrm{R}^{2}$ ) of the linear (Eq. 6) and power relationship (Eq. 7) models is shown for each IM,. Information provided on each plot includes 
Table 2 Observed repair data by liquefaction zone from the Darfield and Christchurch earthquakes combined

\begin{tabular}{|c|c|c|c|c|c|}
\hline Zone & PILCA & XLPE & PILCA HDPE & Other & All materials \\
\hline \multicolumn{6}{|l|}{ A-no liquefaction } \\
\hline Exposure $(\mathrm{km})$ & 2271 & 639 & 93 & 27 & 3030 \\
\hline Repairs & 64 & 1 & 1 & 1 & 67 \\
\hline Repair rate & 0.028 & 0.002 & 0.011 & 0.037 & 0.022 \\
\hline \multicolumn{6}{|l|}{$\mathrm{B}$-liquefaction } \\
\hline Exposure $(\mathrm{km})$ & 711 & 121 & 24 & 4 & 860 \\
\hline Repairs & 362 & 16 & 10 & 2 & 390 \\
\hline Repair rate & 0.509 & 0.132 & 0.419 & 0.545 & 0.454 \\
\hline \multicolumn{6}{|l|}{$\mathrm{C}$-liquefaction, with settlement only } \\
\hline Exposure $(\mathrm{km})$ & 649 & 113 & 23 & 3 & 788 \\
\hline Repairs & 257 & 14 & 6 & 2 & 279 \\
\hline Repair rate & 0.396 & 0.124 & 0.266 & 0.586 & 0.354 \\
\hline \multicolumn{6}{|l|}{ D—liquefaction, with lateral spread } \\
\hline Exposure $(\mathrm{km})$ & 62 & 8 & 1 & 0 & 72 \\
\hline Repairs & 105 & 2 & 4 & $\mathrm{n} / \mathrm{a}$ & 111 \\
\hline Repair rate & 1.698 & 0.242 & 2.969 & $\mathrm{n} / \mathrm{a}$ & 1.548 \\
\hline Total repair rate (both eq's) & 0.143 & 0.022 & 0.094 & 0.098 & 0.118 \\
\hline Total repair rate (Darfield eq) & 0.015 & 0.005 & $\mathrm{n} / \mathrm{a}$ & $\mathrm{n} / \mathrm{a}$ & 0.012 \\
\hline Total zones repair rate (Christchurch eq) & 0.271 & 0.039 & 0.188 & 0.195 & 0.223 \\
\hline
\end{tabular}

the equation of the best-fit model for predicting a mean value of the repair rate, $R_{\text {MEAN }}$, the $\mathrm{R}^{2}$, and the $p$ value for regression significance. Since the repair rate functions are derived from empirical datasets, the observation are characterised by significant natural scatter. Although it is very rare in the literature for empirical functions to be accompanied by estimates of uncertainty (Rossetto et al. 2015), the plots in Fig. 11 also include information on the regression standard error, SE (in terms of $\ln \mathrm{RR}$ for the power relationship models) and an error range encompassing one standard error either side of the median prediction of the fitted model. Since the standard error for power relationship models is in terms of $\ln \mathrm{RR}$, the standard error becomes a multiplicative factor when converted to natural scale.

The plots show that repair rates do not correlate well with PGV even in the nonliquefaction zone. This supports the observations of Tanaka et al. (2008), Fujisaki et al. (2014) and Kwasinki et al. (2014) that only ground deformation should cause damage to buried cables. Well-correlated and significant regressions are also achieved using PGDf $_{\mathrm{V}}$ and PGDf $_{\mathrm{GEOM}}$, which suggests that some cables in this zone may be subjected to subsurface liquefaction. Given that liquefaction is more prevalent when ground shaking is more vigorous and that the zoning study is based on surface evidence of liquefaction only, it is possible that the small number of repairs observed in this zone are the result of zoning misclassification. Due to the small number faults observed, it is not possible to derive a repair rate versus IM model for XLPE, PILCA HDPE or other cable typologies. 

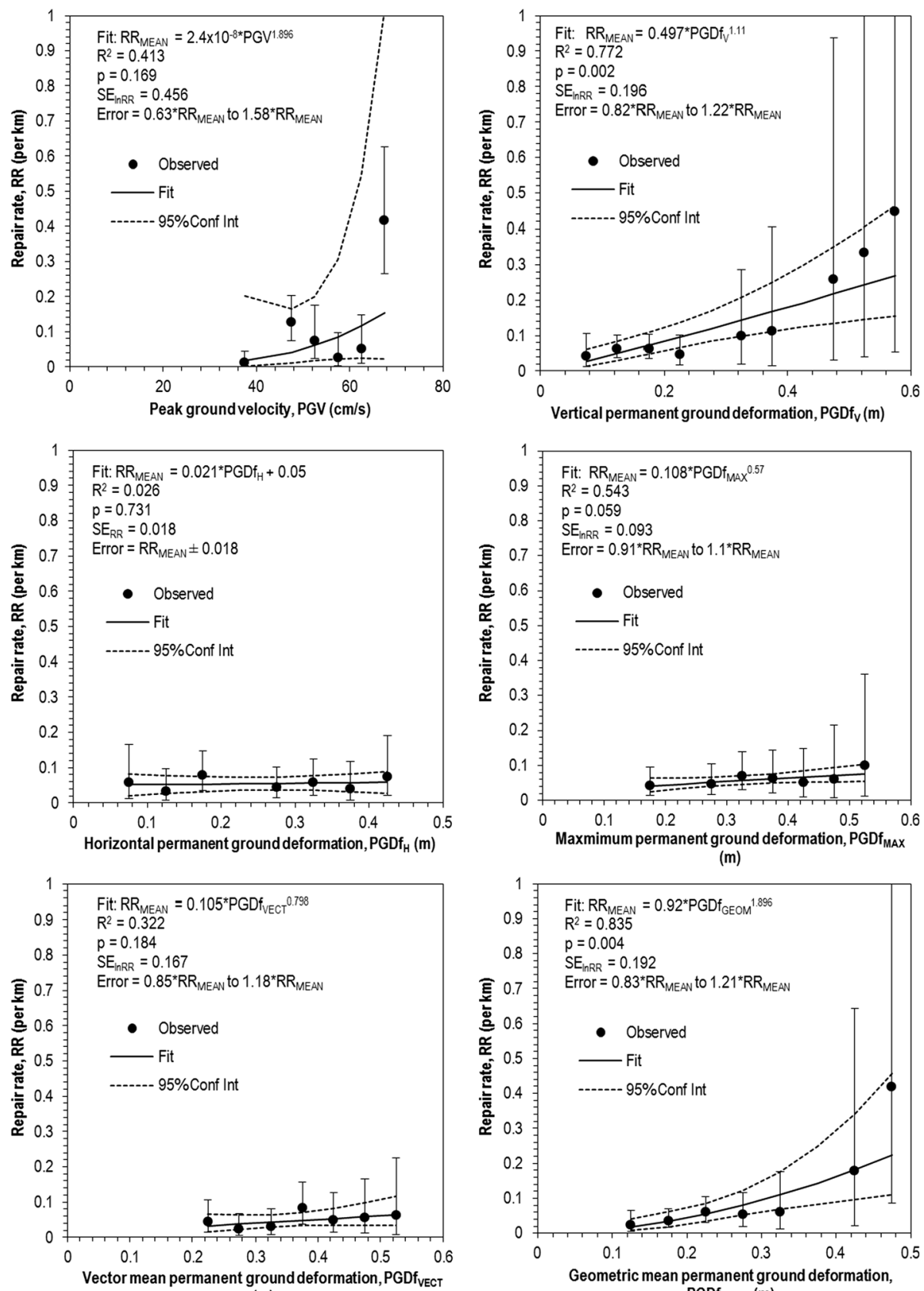

(m)

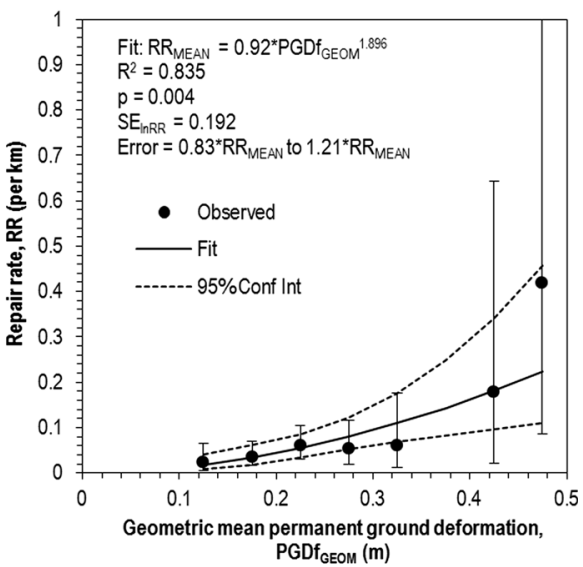

Fig. 11 Plots of repair rates versus candidate intensity measures (IMs) for PILCA cables in Zone A (no liquefaction), including Poisson confidence interval around each observation (error bars), best fit linear regression model (solid line) and confidence interval around best fit (dashed line) 


\subsubsection{Zone B: liquefaction}

Figure 12 shows the repair rate observations and fitted regression models for PILCA cables as a function of each of the candidate IMs. In this zone, $\mathrm{PGDf}_{\mathrm{GEOM}}$ produces the highest $\mathrm{R}^{2}$ value and the only $\mathrm{R}^{2}>0.7$. The regression with this IM is also significant at the $5 \%$ level and the error range is not very large relative to the magnitude of the model predictions. Consequently one can conclude that $\mathrm{PGDf}_{\mathrm{GEOM}}$ is the optimal IM for predicting cable repair rates in liquefied soils. Although more faults are observed amongst the other cable typologies in this zone, they are still few in number. A variety of bin widths have been tested but in every case, once the screening criteria are applied, there remain an insufficient number of observations $(<3)$ on which to perform a meaningful regression for other cable typologies.

\subsubsection{Zone C: liquefaction with settlement only}

Figure 13 shows the repair rate observations and fitted regression models for PILCA cables as a function of each of the candidate IMs. In this zone, $\mathrm{PGDf}_{\mathrm{GEOM}}$ produces the highest $\mathrm{R}^{2}$ value and the only $\mathrm{R}^{2}>0.7$. The regression with this IM is also significant at the $5 \%$ level. However, since there should be no horizontal movement in an area where only settlement is observed, in practice the $\mathrm{PGDf}_{\mathrm{GEOM}}$ model can never be applied since the geometric mean of a set of values cannot be calculated if one of the values is zero. The presence of horizontal movements in the empirical dataset is likely to be due to a combination of LiDAR measurement errors or zoning misclassification. As expected PGV and $\mathrm{PGDf}_{\mathrm{H}}$ are poor predictors in this zone. Since settlement relates to vertical ground deformation, $\mathrm{PGDf}_{\mathrm{V}}$ is the only IM that is physically logical in this zone and would be expected to perform well as a predictor. However. although the regression is significant, it performs only moderately in terms of explanatory power with $\mathrm{R}^{2}=0.6$.. The error range for the $\mathrm{PGDf}_{\mathrm{V}}$ model is still relatively narrow and so this model may be acceptable. As in zone B, once screening criteria are applied, there are insufficient observations to perform a meaningful regression for other cable typologies.

\subsubsection{Zone D: liquefaction with lateral spreading}

Figure 14 shows the repair rate observations and fitted regression models for PILCA cables as a function of each of the candidate IMs. No IM results in a regression with $\mathrm{R}^{2}>0.7$, but the best performing IM is $\operatorname{PGDf}_{H}\left(R^{2}=0.672\right)$, which is what one would expect in the lateral spreading zone. Also as expected $\mathrm{PGV}$ and $\mathrm{PGDf}_{\mathrm{V}}$ perform poorly, further indicating the lack of influence that vertical deformation has in areas where lateral spreading is observed. It is notable that although the $\mathrm{R}^{2}$ of $\mathrm{PGDf}_{\mathrm{GEOM}}(0.635)$ is lower than the $\mathrm{R}^{2}$ for $\mathrm{PGDf}_{\mathrm{H}}$, its standard error is also smaller and its $95 \%$ confidence interval is narrower indicating a lower uncertainty. Consequently, if one is able to specifically identify areas where lateral spreading will occur, then both $\mathrm{PGDf}_{\mathrm{H}}$ and $\mathrm{PGDf}_{\mathrm{GEOM}}$ could be used as the $\mathrm{IM}$ and the final decision rests on the trade-off the practitioner is willing to make between explanatory power and uncertainty. As in zone B, once screening criteria are applied, there are insufficient observations to perform a meaningful regression on other cable typologies. 

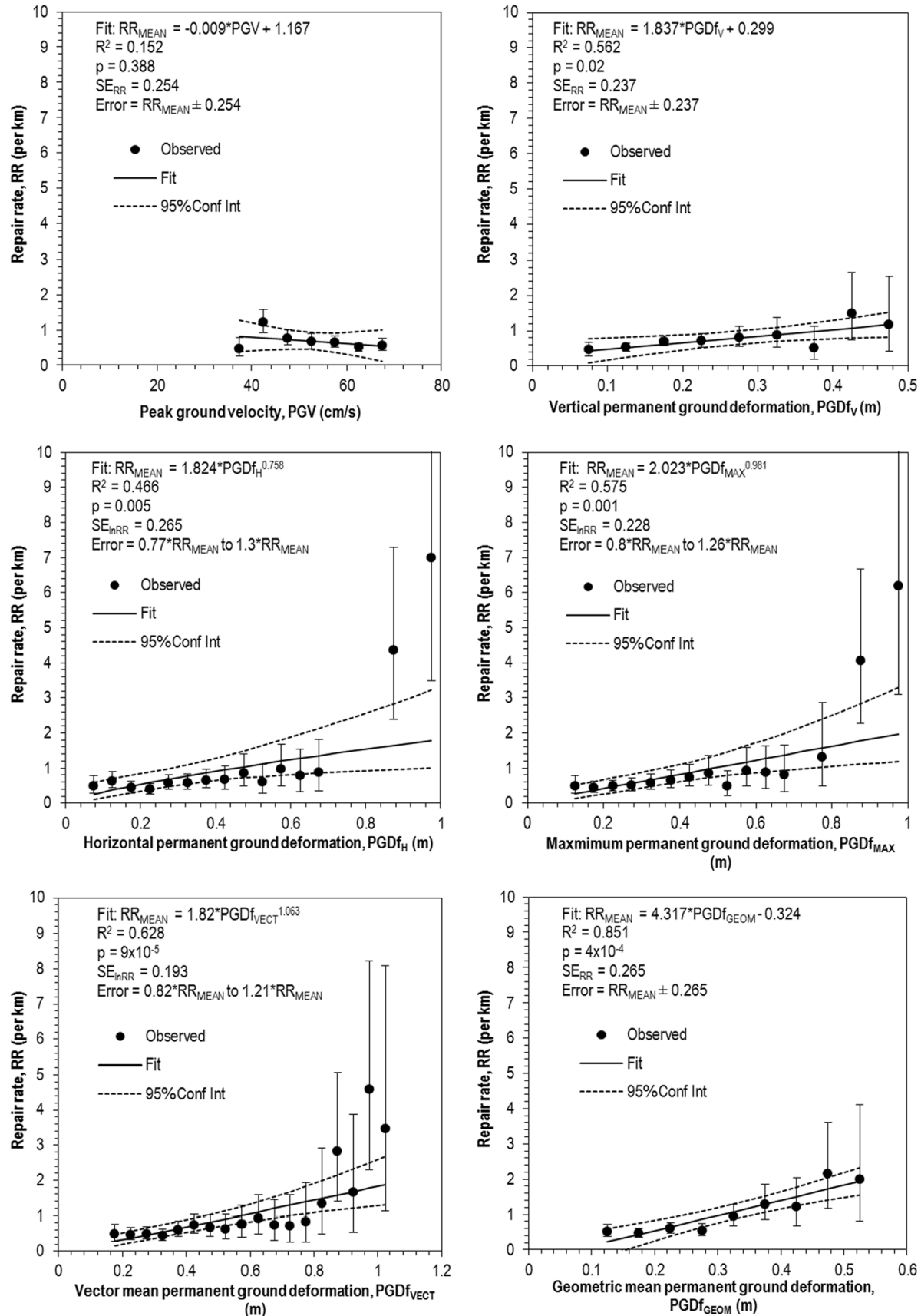

Fig. 12 Plots of repair rates versus candidate intensity measures (IMs) for PILCA cables in Zone B (liquefaction), including Poisson confidence interval around each observation (error bars), best fit linear regression model (solid line) and confidence interval around best fit (dashed line) 

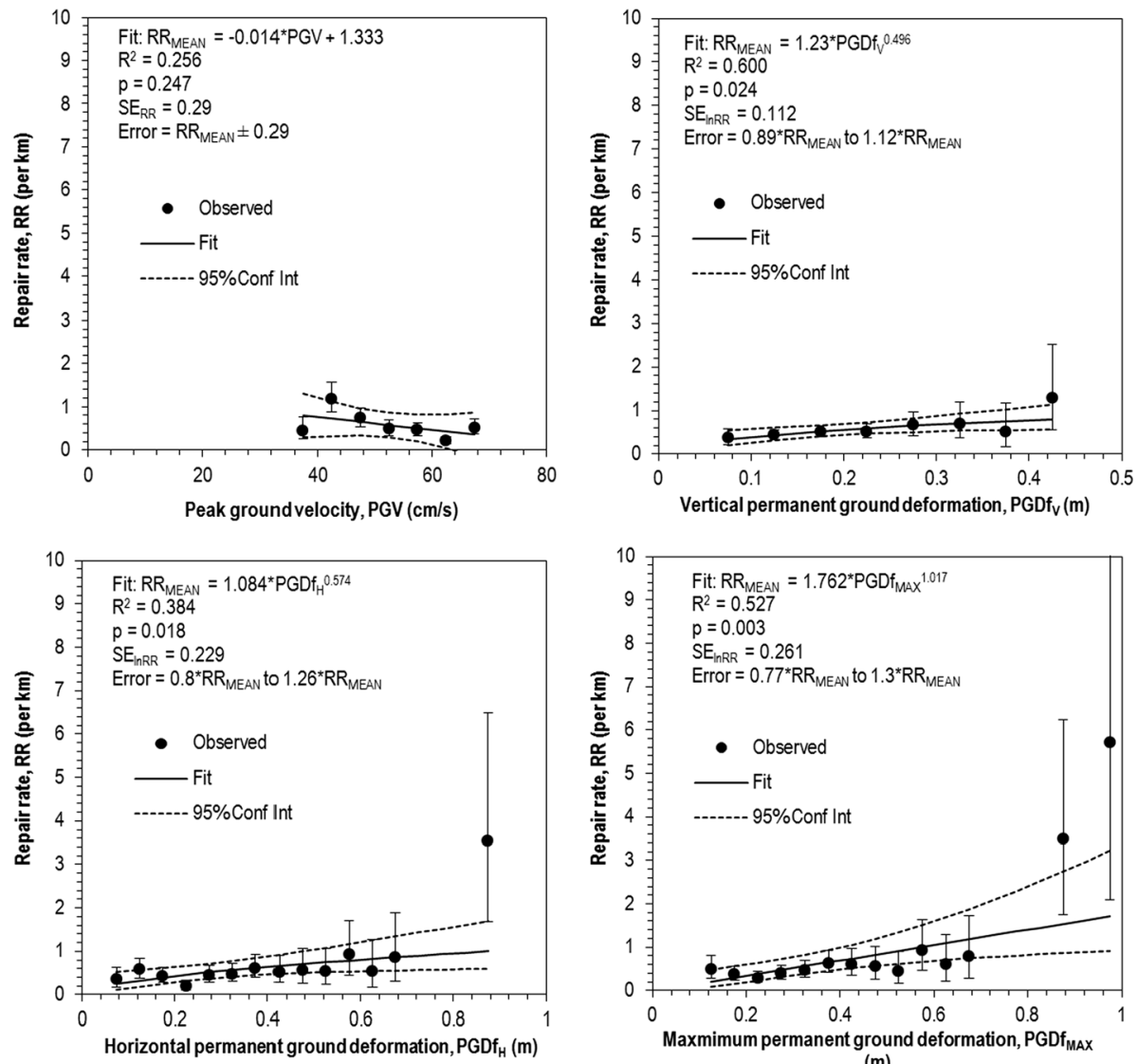

(m)
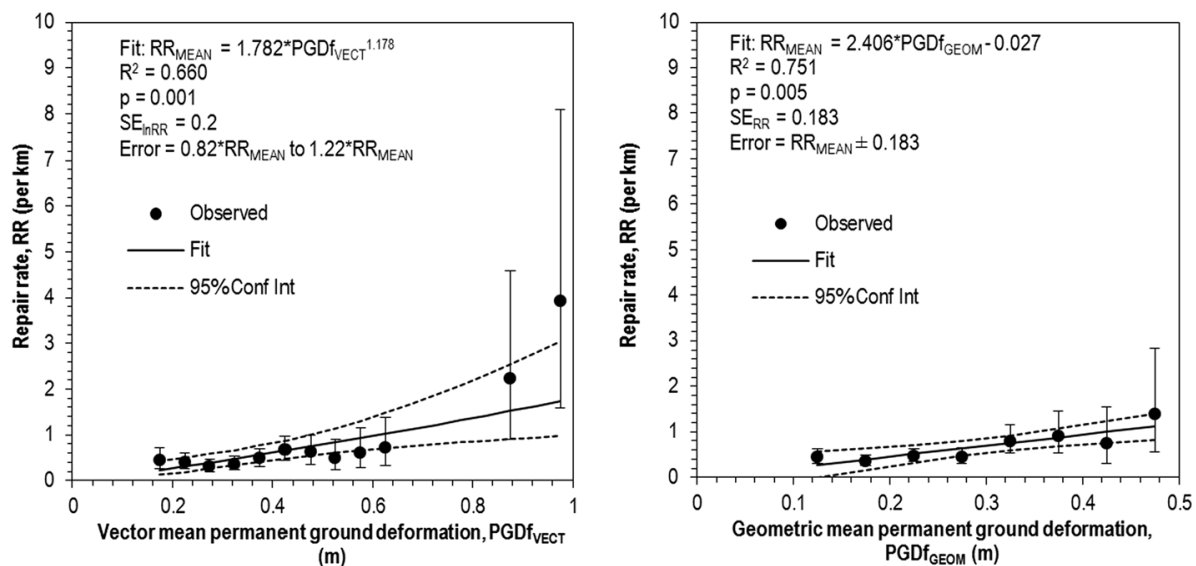

Fig. 13 Plots of repair rates versus candidate intensity measures (IMs) for PILCA cables in Zone C (liquefaction with settlement only), including Poisson confidence interval around each observation (error bars), best fit linear regression model (solid line) and confidence interval around best fit (dashed line) 

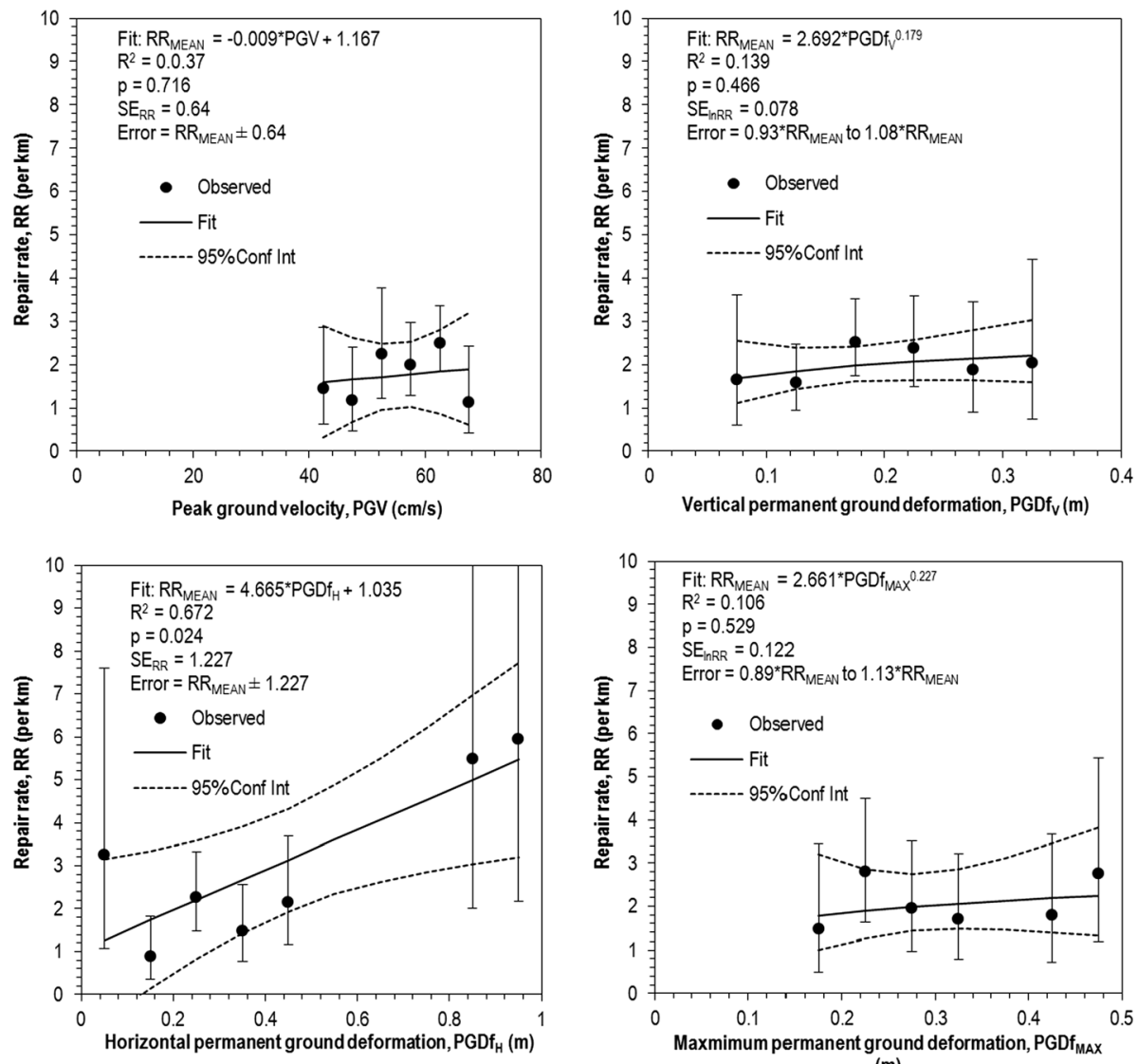

(m)
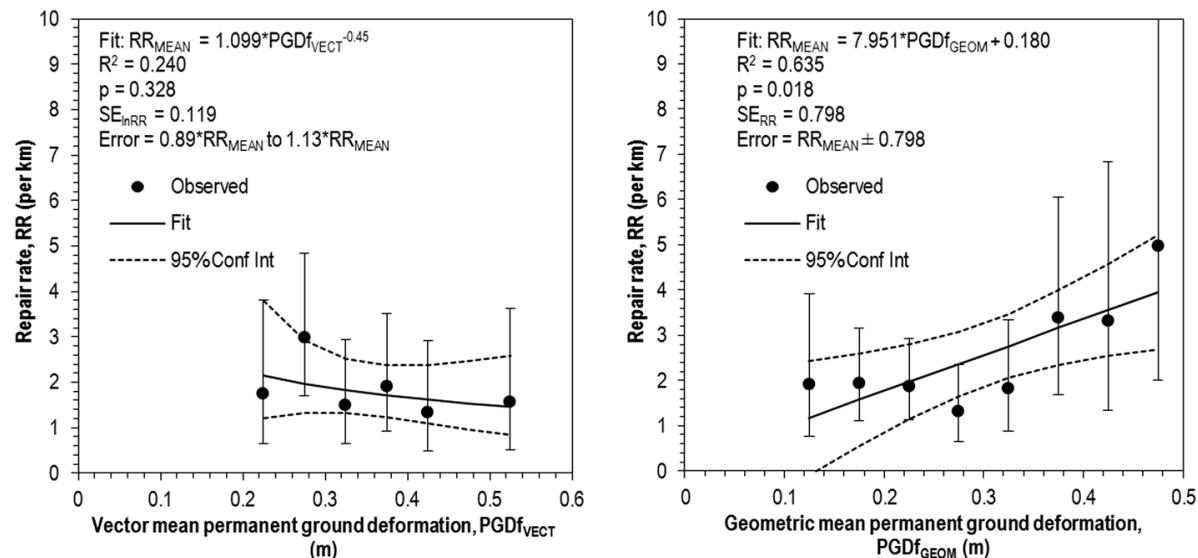

Fig. 14 Plots of repair rates versus candidate intensity measures (IMs) for PILCA cables in Zone D (liquefaction with lateral spread), including Poisson confidence interval around each observation (error bars), best fit linear regression model (solid line) and confidence interval around best fit (dashed line) 


\subsection{Summary of repair rate relationships}

\subsubsection{PILCA cables}

From the preceding analysis it is possible to conclude that ground shaking alone has negligible impact on repair rates compared to liquefaction. In the non-liquefaction zone only permanent ground deformation IMs show good correlations with repair rates but this is likely to be due to data quality issues and resulting misclaassification of liquefaction zones. In any case the resulting repair rate functions are of little value for future fragility analyses since in non-liquefying areas, permanent ground deformations would by definition be estimated to be zero. Figures 11, 12, 13 and 14 show that the majority of data points in Zone A have repair rates in the region of 0.01 to 0.1 repairs per $\mathrm{km}$ whilst in Zones B to D, the majority of data points have repair rates greater than 0.1 repairs per $\mathrm{km}$, with many in excess of 1 repair per $\mathrm{km}$. In areas where liquefaction occurs, PGDf $_{\mathrm{GEOM}}$ is the best performing IM, except in lateral spreading areas where PGDf $_{H}$ performs slightly better but potentially at the cost of increased uncertainty. The repair rate functions associated with the optimal IMs in each zone are summarised in Table 3. The uncertainty associated with each model accompanied the corresponding plots are shown in Figs. 11, 12, 13 and 14.

\subsubsection{Other cable insulation typologies}

The low number of faults in other cable insulation typologies has prevented repair rate versus IM functions being derived for XLPE, PILCA HDPE and 'Other' cable typologies, yet between them they constitute approximately a quarter of the total cable exposure in Christchurch and must be considered in any risk assessment of the electric power system. As summarized by Kakderi and Argyroudis (2014), it is common with pipeline repair rate functions, for the same basic function to be used with a coefficient to account for different material types. A similar approach is proposed for buried cables using the data in Table 2. Taking the PILCA cable repair rate functions as a base model, then the coefficients for alternative typologies can be defined as the ratio of the repair rate in the alternative typology to the repair rate in PILCA cables, not accounting for IM. Therefore to estimate the repair rate for these typologies, one can calculate the repair rate for PILCA cables first and then multiply by the corresponding coefficient. The coefficients for each alternative typology, divided by zone, are shown in Table 4.

Table 3 Optimal IMs and corresponding repair rate functions for each liquefaction analysis zone

\begin{tabular}{ll}
\hline Zone & Repair rate function \\
\hline A-no liquefaction & No reliable relationship \\
B-all liquefaction & $R R=4.317 \times P G D f_{G E O M}-0.324$ \\
C-liquefaction, with settlement only & $R R=1.23 \times P G D f_{V}^{0.496}$ \\
D-liquefaction, with lateral spreading & $R R=4.665 \times P G D f_{H}+1.035$ \\
& $R R=7.951 \times P G D f_{G E O M}+0.18$ \\
\hline
\end{tabular}


Table 4 Proposed coefficients for alternative cable typologies to be applied to base PILCA repair rate functions

\begin{tabular}{llll}
\hline Zone & XLPE & PILCA HDPE & Other \\
\hline A & 0.06 & 0.38 & 1.31 \\
B & 0.26 & 0.82 & 1.07 \\
C & 0.31 & 0.67 & 1.48 \\
D & 0.14 & 1.75 & 0.00 \\
All zones & 0.16 & 0.66 & 0.68 \\
\hline
\end{tabular}

\subsection{Conduction material}

Based on their material properties, Kwasinki et al. (2014) observe that cables that use copper and aluminium as conduction materials (as in the case of Christchurch) should be able to accommodate the moderate liquefaction-induced extensions observed in the two earthquakes, and that other factors primarily affect the fragility of cables. The cable repair dataset includes information on conducting material and so the influence of this factor can be tested. Table 5 summarises the repair rates in each zone for cables classified by conducting material, and also for cables classified by their conducting/insulation material combination.

Analysing the data for cables classified by conducting material alone, it seems there is a clear difference between copper and aluminium cables, with copper cables approximately twice as vulnerable as aluminium cables in all zones. However, $96 \%$ of copper cables are insulated with PILCA, compared to just $61 \%$ of aluminium cables. It has been shown in the preceding analysis that PILCA is considerably more vulnerable than other insulation materials and so it is possible that the discrepancy between copper and aluminium as conducting materials is due to the vulnerability of the corresponding insulation rather than due to the influence of the conducting material itself.

It is more useful therefore to compare the influence of conducting material between cables with the same insulation material. The data for copper XLPE cables is relatively unreliable given that it is based on a low exposure $(34 \mathrm{~km})$ and just two repairs. Comparison within PILCA cables is more useful and shows that across all zones, repair rates for copper cables are higher than for aluminium cables. The linear regression procedure for deriving repair rate functions is applied to copper PILCA and aluminium PILCA cables for each of the liquefaction zones (B, C and D), using the best performing IMs as determined in the preceding sections. Table 6 presents some of the key statistical metrics from the regression analysis.

Table 5 Repair rates calculated in each zone for cables classified by conducting material

\begin{tabular}{lllllll}
\hline Zone & $\begin{array}{l}\text { Copper } \\
\text { All }\end{array}$ & $\begin{array}{l}\text { Aluminium } \\
\text { All }\end{array}$ & $\begin{array}{l}\text { Copper } \\
\text { PILCA }\end{array}$ & $\begin{array}{l}\text { Aluminium } \\
\text { PILCA }\end{array}$ & $\begin{array}{l}\text { Copper } \\
\text { XLPE }\end{array}$ & $\begin{array}{l}\text { Aluminium } \\
\text { XLPE }\end{array}$ \\
\hline A & 0.031 & 0.015 & 0.032 & 0.023 & 0 & 0.002 \\
B & 0.553 & 0.346 & 0.553 & 0.441 & 0.477 & 0.120 \\
C & 0.417 & 0.288 & 0.416 & 0.366 & 0.479 & 0.110 \\
D & 1.862 & 1.104 & 1.851 & 1.392 & 0 & 0.242 \\
All & 0.166 & 0.078 & 0.169 & 0.109 & 0.052 & 0.021 \\
\hline
\end{tabular}


Table 6 Statistical comparison of repair rate functions derived for copper PILCA and aluminium PILCA cables

\begin{tabular}{lllll}
\hline Zone & $\mathrm{IM}$ & $\mathrm{R}^{2}$ Copper PILCA & $\mathrm{R}^{2}$ Aluminium PILCA & $\mathrm{t}$ test $p$ value \\
\hline $\mathrm{B}$ & PGDf $_{\mathrm{GEOM}}$ & 0.682 & 0.897 & 0.559 \\
$\mathrm{C}$ & PGDf $_{\mathrm{V}}$ & 0.795 & 0.163 & 0.554 \\
$\mathrm{C}$ & PGDf $_{\mathrm{GEOM}}$ & 0.729 & 0.818 & 0.057 \\
$\mathrm{D}$ & PGDf $_{\mathrm{H}}$ & 0.275 & 0.138 & 0.146 \\
$\mathrm{D}$ & PGDf $_{\mathrm{GEOM}}$ & 0.316 & 0.666 & 0.342 \\
\hline
\end{tabular}

$\mathrm{R}^{2}$ values for the best model fits are presented and indicate that moderate to wellcorrelated models can be generated for both cable typologies in all zones except zone D, where both IMs result in poor correlations for damage to copper PILCA cables. T-tests are performed to compare the copper PILCA and aluminium PILCA models in each zone and determine whether they are significantly different. The null hypothesis of each t-test is that there is no significant difference (at the $5 \%$ level) between the slopes of regression best fit lines for each typology. In all cases presented in Table 6 the $p$ value is greater than 0.05 , so the null hypothesis cannot be rejected. There is insufficient evidence from the data to conclude that conducting material influences repair rates, which corresponds to the observations of Kwasinki et al. (2014). This can be further illustrated by the plots in Fig. 15. These show that not only do the confidence intervals for the two materials overlap but more notably, in each case the best fit line of one material is contained within the confidence bounds of the other, indicating that there is no significant difference between them.

\subsection{Age of cables}

Another potential factor that may influence the repair rate is the age of the cables. One might expect that older cables would be more vulnerable leading to higher repair rates observed in the data. The dataset provided by Orion includes information on the decade in which each cable was laid. A notable statistic is that $87 \%$ of XLPE cables were laid in the 2000s and accordingly, all but one of the faults observed amongst XLPE cable occurred on cables laid during this decade. Consequently a comparison of repair rates with age amongst XLPE cables is not possible. However, this analysis can be performed for PILCA cables and the results are summarized in Table 7 and plotted in Fig. 16, where the age of the cable is taken from the midpoint of each decade to 2010, the year of the first earthquake. The plots do not show any strong trend for repair rate increasing with age in any of the four zones. Linear regression models have been fit for each zone both directly and using logarithmic transformations. None of the models are significant at the 5\% level and the highest value of $R^{2}$ is 0.213 . This indicates that in Christchurch, age did not influence cable fragility during the earthquakes.

\section{Cable fragility curves}

Since failure probability depends on length as well as IM, one way to visualise this metric is by plotting a suite of curves on the same axes for different cable lengths. Examples of cable fragility curve suites are shown in Fig. 17, which plots the failure probability of 

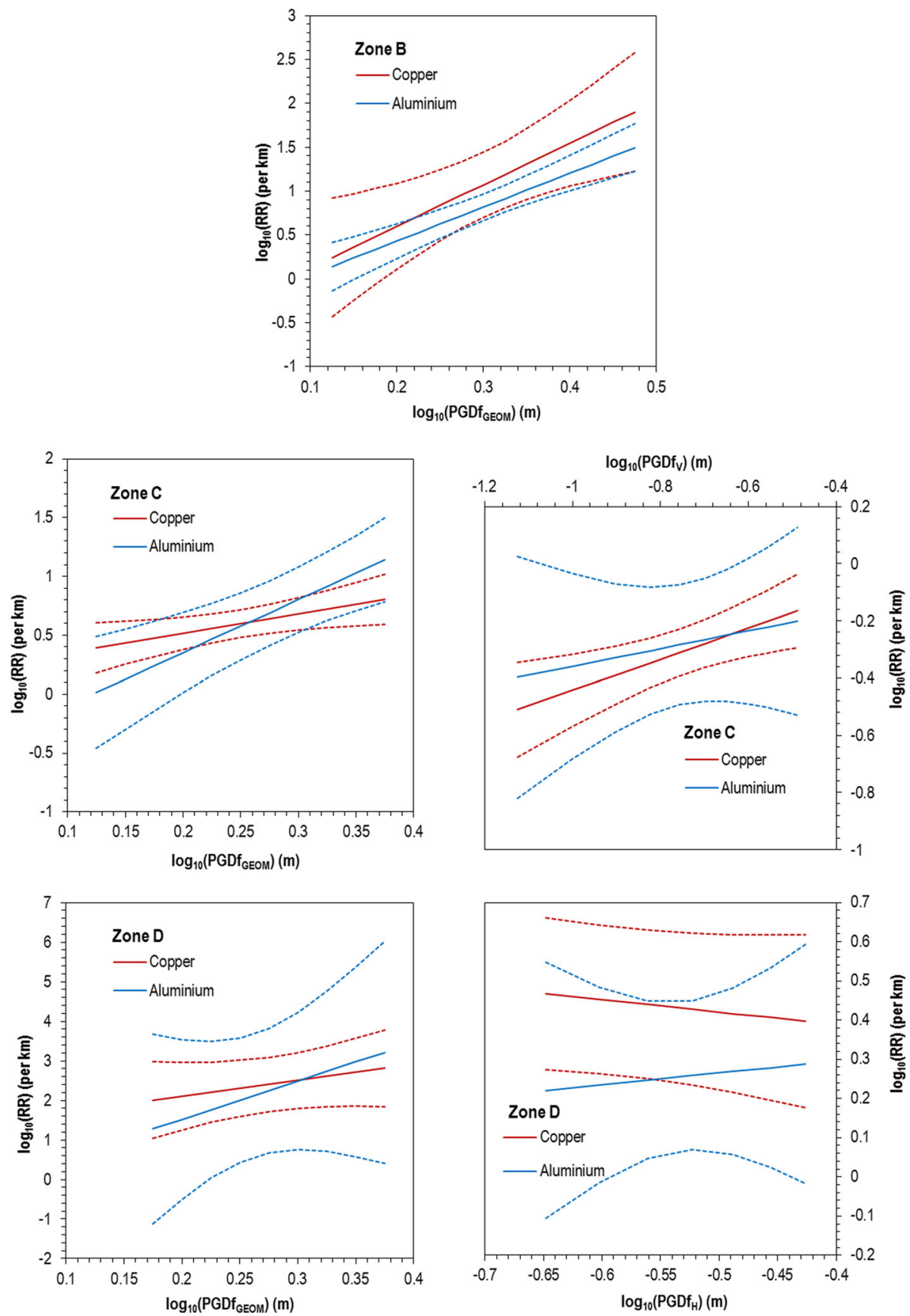

Fig. 15 Linear regression model fits and confidence intervals for copper PILCA and aluminium PILCA cables for selected IMs in each zone 
Table 7 Repair rates for PILCA cables in each zone by age (blank cells indicate that the one or more of the screening criteria have not been met)

\begin{tabular}{lcccccc}
\hline Decade laid & Age & Zone A & Zone B & Zone C & Zone D & All zones \\
\hline $2000 \mathrm{~s}$ & 5 & & 0.392 & 0.359 & & 0.084 \\
$1990 \mathrm{~s}$ & 15 & 0.019 & 0.259 & 0.159 & 1.379 & 0.064 \\
$1980 \mathrm{~s}$ & 25 & 0.043 & 0.341 & 0.274 & 0.991 & 0.104 \\
$1970 \mathrm{~s}$ & 35 & 0.018 & 0.641 & 0.513 & 2.020 & 0.181 \\
$1960 \mathrm{~s}$ & 45 & 0.032 & 0.557 & 0.406 & 1.983 & 0.160 \\
$1950 \mathrm{~s}$ & 55 & 0.037 & 0.591 & 0.514 & 1.466 & 0.183 \\
$1940 \mathrm{~s}$ & 65 & & 0.259 & 0.221 & & 0.075 \\
$1930 \mathrm{~s}$ & 75 & & 0.397 & 0.169 & & 0.122 \\
\hline
\end{tabular}

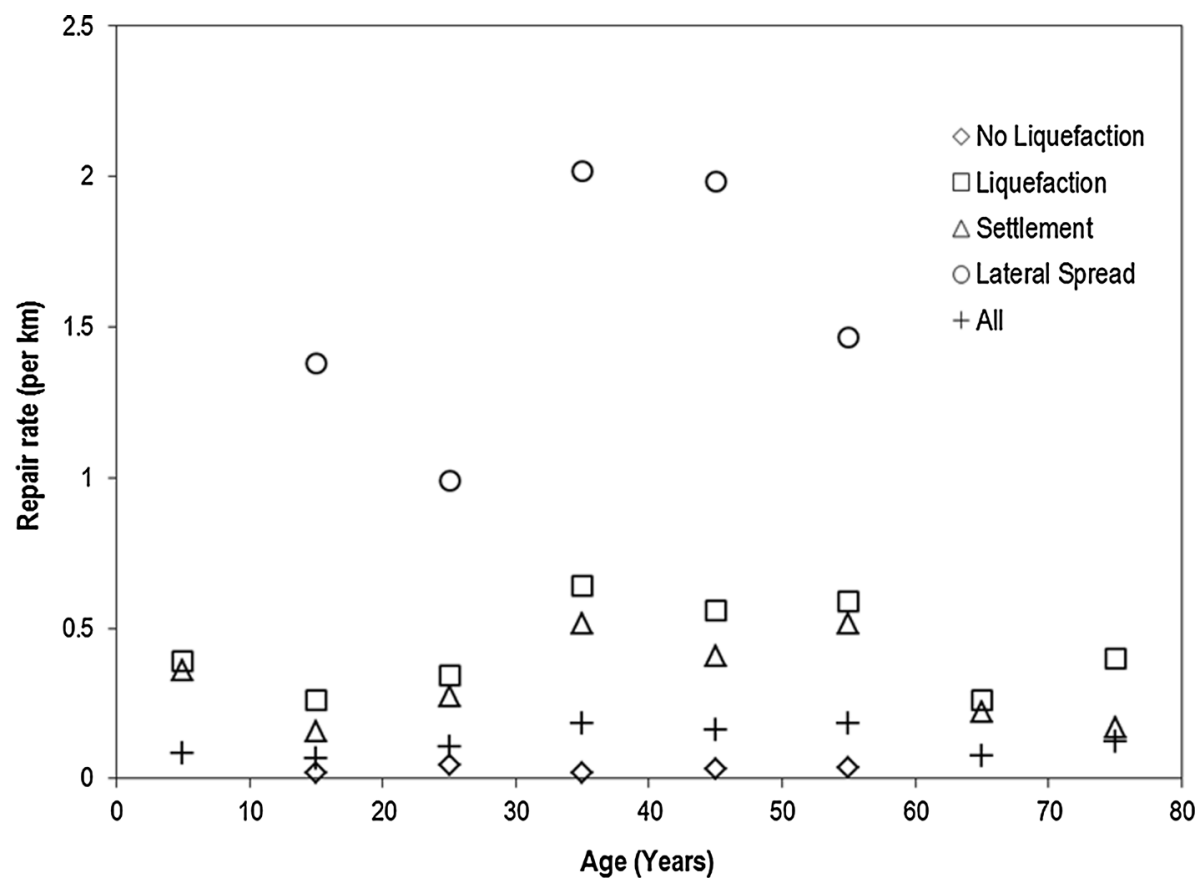

Fig. 16 Plot of repair rates versus age in each zone for PILCA cables

different lengths of cables in Zones $\mathrm{C}$ (settlement only) and D (lateral spread), using $\mathrm{PGDf}_{\mathrm{GEOM}}$ as an IM. For the PILCA curve, repair rates have been calculated using the corresponding functions plotted in Figs. 13 and 14, whilst for the XLPE curve, repair rates have been calculated by applying the relevant material coefficient from Table 4 to the PILCA repair rates. 

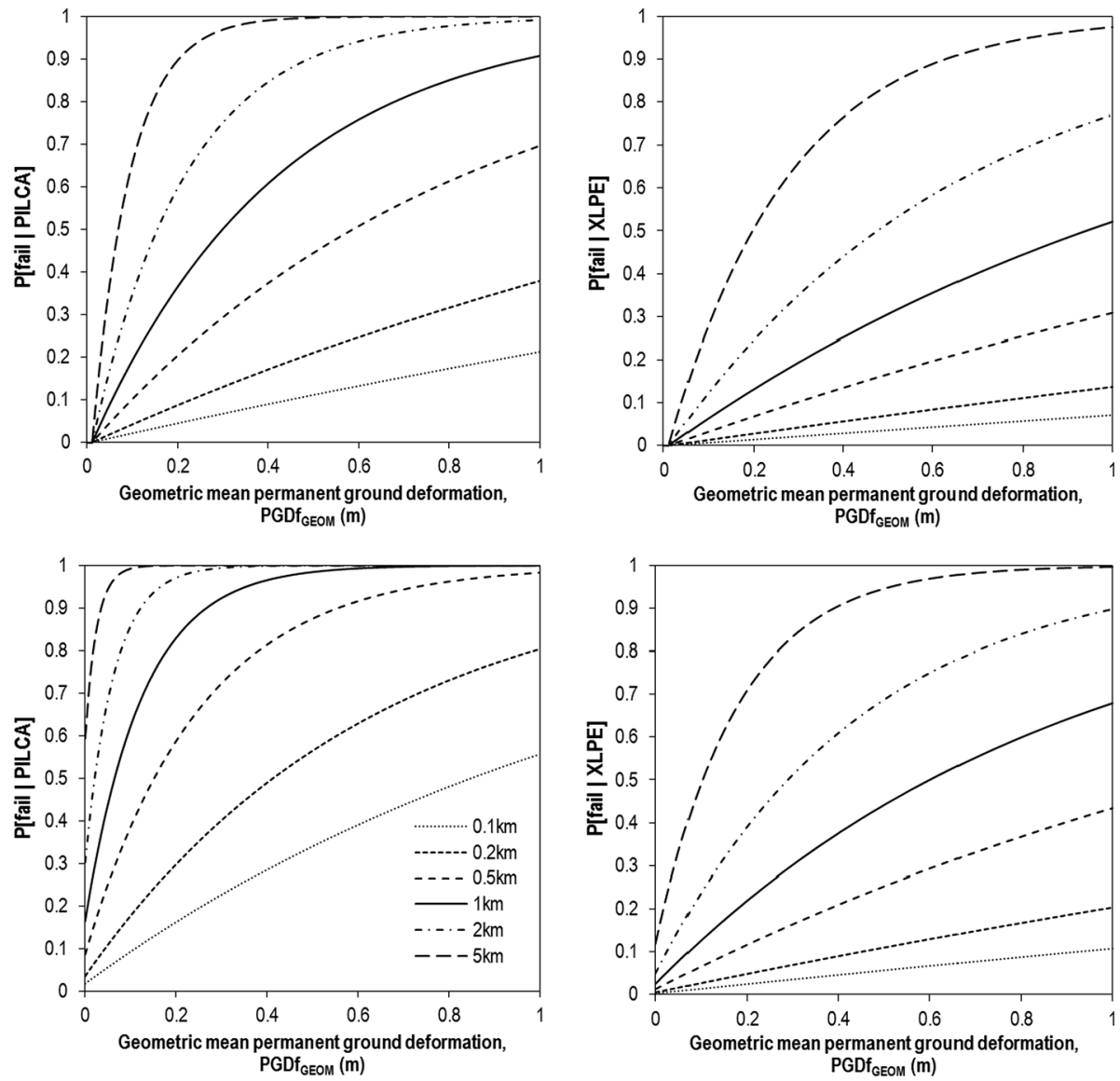

Fig. 17 Example suite of fragility curves for PILCA and XLPE cables exposed to settlement only (top row) and to lateral spread (bottom row) measured in terms of PGDf. (Note legend is the same for all graphs)

\section{Conclusions}

This study has used the observations from Christchurch to produce some of the first empirical repair rate functions for buried cables with respect to ground shaking and liquefaction-induced ground deformation. As an empirical dataset, it is characterised by significant natural scatter and this is captured by the inclusion of confidence intervals and uncertainty measurements on the regression plots. The scatter implies that the functions are most usefully employed as part of a probabilistic assessment but it is ultimately up to the individual analyst to process the information provided and make their own judgment as to whether the scale of error is acceptable based on specific project/application requirements.

Insulation material is a critical factor that influences cable damage as demonstrated by the fact that repair rates in PILCA cables are considerably higher than those observed in XLPE cables. Since there are insufficient damage data to derive specific repair rate functions for materials other than PILCA, all IM analysis has been conducted for PILCA cables and coefficients, derived from the overall repair rates, are proposed to modify the 'base' PILCA functions for other materials. 
The analysis confirms that liquefaction is the main hazard affecting buried cables, with very low repair rates observed in areas where no liquefaction occurred and even this may be the result of misclassification. There is a poor correlation between repair rate and PGV in this zone, whereas $\mathrm{PDf}_{\mathrm{V}}$ and $\mathrm{PGDf}_{\mathrm{GEOM}}$ show good correlations. This suggests that subsurface liquefaction, which is not accounted for in the liquefaction zoning, may be the primary driver here and that ground shaking alone has only minimal impact on buried cables.

Within the liquefaction zone it is notable that lateral spreading is considerably more damaging than vertical settlement alone. In areas where lateral spreading was observed,

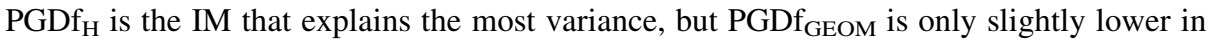
this regard but has smaller uncertainty bounds and so may be considered to be more acceptable to some engineers. In areas where only settlement was observed, PGDf $_{\text {GEOM }}$ is the best performing IM in terms of variance explained. However theoretically PGDf $_{\mathrm{GEOM}}$ cannot be calculated in a settlement-only zone and so it is advised to use the function with $\mathrm{PGDf}_{\mathrm{V}}$ instead, which has moderate correlations and low uncertainty. When no distinction is made between settlement and lateral spreading, the best performing model is predictably one of the composite IMs, PGDf $\mathrm{GEOM}_{\text {. }}$

Other factors such as conducting material and age have also been considered but there appears to be no trend between repairs and increasing age, while the difference between the repair rates of copper and aluminium cables is not statistically significant. This analysis confirms the findings of Kwasinki et al. (2014) that conduction material should not affect vulnerability.

This analysis has been based on data from two earthquakes in Christchurch, which are characterised by scatter and moderate correlations and in the longer term there is a need to validate or enhance these functions with data from other earthquakes. However, since they are the first of their kind, and there are limited alternatives for addressing buried cables in the literature, the proposed functions are a useful tool for the engineering community for application in safety and seismic risk assessments of electric power networks.

Acknowledgements The authors are grateful to Orion New Zealand Limited for providing maps and data and in particular Dave Brannigan, Peter Elliott, Ricki-Lee Teague, John O'Donnell and Shane Watson, for their time and availability. We would also like to thank Sjoerd van Ballegooy of Tonkin and Taylor for providing data on observed land damage categories and Andrew Massie of the Christchurch Polytechnic Institute of Technology for permitting use of images. Funding for this research project has been provided by the UK Engineering and Physical Sciences Research Council and the Willis Research Network, through the Urban Sustainability and Resilience program at University College London.

Open Access This article is distributed under the terms of the Creative Commons Attribution 4.0 International License (http://creativecommons.org/licenses/by/4.0/), which permits unrestricted use, distribution, and reproduction in any medium, provided you give appropriate credit to the original author(s) and the source, provide a link to the Creative Commons license, and indicate if changes were made.

\section{References}

Adachi T, Ellingwood BR (2008) Serviceability of earthquake-damaged water systems: effects of electrical power availability and power backup systems on system vulnerability. Reliab Eng Syst Saf 93:78-88 Akkar S, Bommer JJ (2007) Empirical prediction equations for peak ground velocity derived from strongmotion records from Europe and the Middle East. Bull Seismol Soc Am 97(2):511-530

American Lifelines Alliance (ALA) (2001) Seismic fragility of water systems part 1-guideline. American Society of Civil Engineers (ASCE), Reston, VA 
Boore DM, Joyner WB, Fumal TE (1997) Equations for estimating horizontal response spectra and peak accelerations from Western North American earthquakes: a summary of recent work. Seismol Res Lett 68(1):128-153

Brackley HL (2012) Review of liquefaction hazard information in eastern Canterbury, including Christchurch City and parts of Selwyn, Waimakariri and Hurunui Districts, Report No R12/83, Environment Canterbury Regional Council, Christchurch, New Zealand

Bradley BA, Quigley MC, van Dissen RJ, Litchfield NJ (2014) Ground motion and seismic source aspects of the Canterbury earthquake sequence. Earthq Spectra 30(1):1-15

Canterbury Geotechnical Database (CGD) (2012a) Vertical ground surface movements, Map Layer CGD0600-23 July 2012. https://canterburygeotechnicaldatabase.projectorbit.com/. Accessed 9 Oct 2014

Canterbury Geotechnical Database (CGD) (2012b) Horizontal ground surface movements, Map Layer CGD0700-23 July 2012. https://canterburygeotechnicaldatabase.projectorbit.com/. Accessed 9 Oct 2014

Canterbury Geotechnical Database (CGD) (2013) LiDAR and digital elevation models, Map Layer CGD0500-03 Aug 2013. https://canterburygeotechnicaldatabase.projectorbit.com/. Accessed 9 Oct 2014

Cavalieri F, Franchin P, Pinto PE (2014a) Fragility functions of electric power stations. In: Pitilakis K, Crowley H, Kaynia A (eds) SYNER-G: typology definition and fragility functions for physical elements at seismic risk, vol 27., Geotechnical, geological and earthquake engineeringSpringer, Dordrecht, pp 157-185

Cavalieri F, Franchin P, Buriticá Cortes JAM, Tesfamariam S (2014b) Models for seismic vulnerability analysis of power networks: comparative assessment. Comput Aided Civil Infrastruct Eng 29(8):590-607

de Smith MJ, Goodchild MF, Longley PA (2009) Geospatial analysis: a comprehensive guide to principles, techniques and software tools, 3rd edn. Troubador, Leicester

Dobson AJ, Kuulasmaa K, Eberle E, Scherer J (1991) Confidence intervals for weighted sums of Poisson parameters. Stat Med 10:457-462

Eidinger J, Tang A (eds) (2012) Christchurch, New Zealand earthquake sequence of Mw 7.1 September 04, 2010, Mw 6.3 February 22, 2011, Mw 6.0 June 13, 2011: lifelines performance, technical council on lifeline earthquake engineering, Monograph 40. ASCE, Reston, VA

Esposito S, Giovinazzi S, Elefante L, Iervolino I (2013) Performance of the L'Aquila (central Italy) gas distribution network in the $2009\left(\mathrm{M}_{\mathrm{W}}\right.$ 6.3) earthquake. Bull Earthq Eng 11:2447-2466

Fujisaki E, Takhirov S, Xie Q, Mosalam KM (2014) Seismic vulnerability of power supply: lessons learned from recent earthquakes and future horizons of research. In: Cunha A, Caetano E, Ribeiro P, Muller G (eds) Proceedings of 9th international conference on structural dynamics (EURODYN 2014). European Association for Structural Dynamics, Porto, Portugal, pp 345-350

Green RA, Cubrinovksi M, Cox B, Wood C, Wotherspoon L, Bradley BA, Maurer B (2014) Select liquefaction case histories from the 2010-11 Canterbury earthquake sequence. Earthq Spectra 30(1):131-154

Hwang HHM, Huo J-R (1998) Seismic fragility analysis of electric substation equipment and structures. Probab Eng Mech 97:107-116

Hwang HHM, Lin H, Shinozuka M (1998) Seismic performance assessment of water delivery systems. J Infrastruct Syst 4:118-125

Isoyama R, Ishida E, Yune K, Shirozu T (2000) Seismic damage estimation procedure for water supply pipelines. In: Paper no 1762, 12th world conference on earthquake engineering, Auckland, New Zealand, International Association for Earthquake Engineering

Kakderi K, Argyroudis S (2014) Fragility functions of water and waste-water systems. In: Pitilakis K, Crowley H, Kaynia A (eds) SYNER-G: typology definition and fragility functions for physical elements at seismic risk, vol 27., Geotechnical, geological and earthquake engineeringSpringer, Dordrecht, pp 221-258

Kongar I, Esposito S, Giovinazzi S (2015) Post-earthquake assessment and management for infrastructure systems: learning from the Canterbury (New Zealand) and L'Aquila (Italy) earthquakes. B Earthq Eng. doi:10.1007/s10518-015-9761-y

Kramer S (2013) Lateral spreading. In: Bobrowsky PT (ed) Encyclopaedia of natural hazards. Springer Science and Business, Dordrecht, p 623

Kwasinki A, Eidinger J, Tang A, Tudo-Bornarel C (2014) Performance of electric power systems in the 2010-2011 Christchurch, New Zealand, earthquake sequence. Earthq Spectra 30(1):205-230 
Leprince S, Bardot S, Ayoub F, Avouac JP (2007) Automatic and precise ortho-rectification, coregistration, and subpixel correlation of satellite images, application to ground deformation measurements. IEEE Trans Geosci Remote Sens 45:1529-1558

Maurer B, Green RA, Cubrinovski M, Bradley BA (2014) Evaluation of the liquefaction potential index for assessing liquefaction hazard in Christchurch, New Zealand. J Geotech Geoenviron Eng. doi:10.1061/ (ASCE)GT.1943-5606.0001117

National Institute of Building Sciences (NIBS) (2003) HAZUS ${ }^{\circledR M H}$ Technical Manual, NIBS, Washington, $\mathrm{DC}$

Newmark NM, Hall WJ (1982) Earthquake spectra and design. Geotechnique 25(2):139-160

Nuti C, Rasulo A, Vanzi I (2007) Seismic safety evaluation of electric power supply at urban level. Earthquake Eng Struct Dyn 36:245-263

Nuti C, Rasulo A, Vanzi I (2010) Seismic safety of network structures and infrastructures. Struct Infrastruct Eng 6(1-2):95-110

O'Rourke TD, Stewart HE, Jeon S-S (2001) Geotechnical aspects of lifelines engineering. Geotech Eng 149(1):13-26

O'Rourke TD, Jeon S-S, Toprak S, Cubrinovski M, Jung JK (2012) Underground lifeline system performance during the Canterbury earthquake sequence. In: 15th world conference on earthquake engineering, Lisbon, Portugal, 24th-28th September 2012, International Association for Earthquake Engineering

O'Rourke TD, Jeon S-S, Toprak S, Cubrinovski M, Hughes M, van Ballegooy S, Bouziou D (2014) Earthquake response of underground pipeline networks in Christchurch, New Zealand. Earthq Spectra 30(1):183-204

Orion (2009) Asset management plan. Orion New Zealand Ltd, Christchurch, New Zealand

Park J, Nojima N, Reed DA (2006) Nisqually earthquake electric utility analysis. Earthq Spectra 22(2):491-509

Pineda-Porras O, Najafi M (2010) Seismic damage estimation for buried pipelines: challenges after three decades of progress. J Pipeline Syst Eng 1:19-24

Pineda-Porras O, Ordaz M (2010) Seismic fragility formulations for segmented buried pipeline systems including the impact of differential ground subsidence. J Pipeline Syst Eng 1:141-146

Rossetto T, Ioannou I, Grant DN (2015) Existing empirical vulnerability and fragility functions: compendium and guide for selection, GEM Technical Report 2015-1, GEM Foundation, Pavia, Italy

Tanaka K, Yamazaki Y, Okazawa T, Suzuki T, Kishimoto T, Iwata K (2008) Experiment on seismic disaster characteristics of underground cables. In: 14th world conference on earthquake engineering, Beijing, China, 12th-17th October 2008, International Association for Earthquake Engineering

Toprak S, Taskin F (2006) Estimation of earthquake damage to buried pipelines caused by ground shaking. Nat Hazards 40(1):1-24

Ulm K (1990) A simple method to calculate the confidence interval of a standardized mortality ratio. Am J Epidemiol 131(2):373-375

US Geological Survey (USGS) (2015a) USGS ShakeMap: South Island of New Zealand Saturday September 4th, 2010. http://earthquake.usgs.gov/earthquakes/shakemap/global/shake/2010atbj/. Accessed 1 Mar 2016

US Geological Survey (USGS) (2015b) USGS ShakeMap: South Island of New Zealand Tuesday February 22nd, 2011. http://earthquake.usgs.gov/earthquakes/shakemap/global/shake/b0001igm/. Accessed 1 March 2016

van Ballegooy S, Malan P, Lacrosse V, Jacka ME, Cubrinovski M, Bray JD, O’Rourke TD, Crawford SA, Cowan H (2014) Assessment of liquefaction-induced land damage for residential Christchurch. Earthq Spectra 30(1):31-55

Vanzi I (1996) Seismic reliability of electric power networks: methodology and application. Struct Safe 18(4):311-327

Wald DJ, Lin K-W, Quitoriano V (2008) Quantifying and qualifying USGS ShakeMap uncertainty, OpenFile Report 2008-1238, US Geological Survey, Reston, VA

Wang Y (2013) Seismic risk assessment of water supply systems. In: Tesfamariam S, Goda K (eds) Handbook of seismic risk analysis and management of civil infrastructure systems. Woodhead Publishing Ltd, Cambridge, pp 659-681

Yamada S, Orense R, Cubrinovski M (2011) Geotechnical damage due to the 2011 Christchurch, New Zealand. Int Soc Soil Mech Geotech Eng (ISSGME) Bull 5(2):27-45 